\title{
Validating a Method to Ensure the Destruction of Salmonella on Product Surfaces During Impingement Cooking
}

\author{
Jeffrey J. Sindelar ${ }^{1 *}$, Robert Hanson ${ }^{2}$, Kathleen A. Glass ${ }^{3}$, Andrew L. Milkowski ${ }^{1}$, \\ Russell P. McMinn ${ }^{1}$, and Jordan Nehls ${ }^{1}$ \\ ${ }^{1}$ Meat Science \& Animal Biologics Discovery, University of Wisconsin-Madison, Madison, WI 53706, USA \\ ${ }^{2}$ HansonTech LLC, Hudson, WI 54016, USA \\ ${ }^{3}$ Food Research Institute, University of Wisconsin-Madison, Madison, WI 53706, USA \\ *Corresponding author. Email: jsindelar@wisc.edu (Jeffrey J. Sindelar)
}

\begin{abstract}
This study investigated the effectiveness of cooking processes that incorporated hydrated surface lethality (HSL) steps for ensuring the reduction of Salmonella on the surfaces of small-dimension meat and poultry products cooked using short-duration, high-temperature impingement oven processes. Whole-muscle chicken tenders ( $3 \%$ fat), beef patties $(10 \%$ and $30 \%$ fat), pork patties (10\% and 30\% fat), and chicken patties (10\% and $20 \%$ fat) were surface inoculated with a 5 -strain mixture of Salmonella to yield 8 log colony-forming units/g, then cooked in a two-zone impingement oven using either dry heat or steam-humidified HSL processes. The HSL steps used steam injection to control the wet-bulb temperature at either $71.1^{\circ} \mathrm{C}$ or $82.2^{\circ} \mathrm{C}$. Dry-heat cooking processes using a dry-bulb temperature of $204.4^{\circ} \mathrm{C}$ and no steam-injected HSL steps failed to consistently achieve a $6.5 \mathrm{log}$ reduction of Salmonella on chicken tenders and the low-fat patty products $(\leq 10 \%$ fat). In contrast, processes incorporating an HSL step using an $82.2^{\circ} \mathrm{C}$ wet-bulb temperature in one or both zones resulted in $\geq 6.5 \log$ reductions of Salmonella for all products. Sufficient reductions were achieved regardless of whether this $82.2^{\circ} \mathrm{C}$ wet-bulb HSL step was incorporated before or after a dry-cook step. Processes that incorporated an HSL step using a $71.1^{\circ} \mathrm{C}$ wet-bulb temperature in both zones also resulted in reductions $\geq 6.5 \log$ for all products. Processes using a $71.1^{\circ} \mathrm{C}$ wet-bulb HSL step in only one zone delivered $\geq 6.5 \mathrm{log}$ reduction for all of the patty products. However, the one-zone $71.1^{\circ} \mathrm{C} H S L$ step achieved $\geq 6.5 \log$ reduction in chicken tenders only if used in the first zone of the two-zone oven. When the $71.1^{\circ} \mathrm{C}$ HSL step was used in the second zone for chicken tenders after using dry heat in the first zone, the target reduction of $6.5 \log$ was not achieved. This research successfully validated approaches to ensure $\geq 6.5 \log$ reduction of Salmonella on product surfaces.
\end{abstract}

Key words: thermal inactivation, Food Safety and Inspection Service Appendix A, Salmonella, hydrated surface lethality, impingement cooking

Meat and Muscle Biology 5(1): 26, 1-20 (2021)

doi:10.22175/mmb.12248

Submitted 26 January 2021

Accepted 26 April 2021

\section{Introduction}

Most meat processors in the United States use Food Safety and Inspection Service Appendix A (USDA, 1999) to ensure sufficient thermal lethality for the myriad array of precooked products that are manufactured every day using countless different cooking processes. The thermal lethality guidelines in Appendix A are based on published research by
Goodfellow and Brown (1978) and include a critical parameter of $6.5 \mathrm{log}$ reduction for Salmonella. In their study, large cuts of Salmonella-inoculated beef were cooked using processes that lasted several (2-6) hours. The Appendix A guidelines are currently being applied to a vast variety of products that were never investigated in the original study, including smalldimension products cooked in belt-fed, high-capacity, continuous ovens such as impingement ovens that use high-temperature, short-duration processes of less 
than 10 min. Although Goodfellow and Brown (1978) tested both dry-heat and high-humidity cooking processes, their study did not test high-temperature, shortduration cooking processes that rapidly dehydrate product surfaces and may alter the heat tolerance of pathogens. The need for hydrated product surfaces to promote pathogen lethality is recognized in the 1999 version of Appendix A but only indirectly through humidity guidelines that are impractical for many products. These humidity guidelines incorrectly infer that specific relative humidity levels alone will lead to sufficient pathogen reductions on product surfaces. Thus, there is a need for a more reliable method to ensure that sufficient reductions of Salmonella are achieved.

In 2017, the USDA updated the Appendix A guidelines to include new relative humidity requirements (USDA, 2017). Under the new guidelines, cooking processes shorter than $60 \mathrm{~min}$ would be required to maintain a relative humidity $\geq 90 \%$ for the entire process. The high-temperature, short-duration cooking processes used in impingement, cross-flow, and spiral ovens (hereafter referred to as impingement ovens), therefore, would be required to follow this guideline. However, the $90 \%$ relative humidity option cannot be used in impingement ovens that are most often run at dry-bulb temperatures of $175^{\circ} \mathrm{C}$ to $260^{\circ} \mathrm{C}$ and $2 \%$ to $8 \%$ relative humidity. Therefore, impingement processes cannot conform to the 2017 Appendix A relative humidity guidelines.

Impingement ovens use high-velocity, low-humidity hot air processes to rapidly (e.g., $<15 \mathrm{~min}$ ) dry product surfaces to promote Maillard browning while the product interior remains hydrated. In addition to browning the product, the rapid surface drying occurring during impingement cooking can also quickly dehydrate bacteria on the surfaces, thus potentially creating desiccated, heat-tolerant pathogens capable of surviving the cooking process (Sindelar et al., 2016). This occurrence is caused by a fundamental process limitation whereby the relative humidity levels in impingement oven processes are inherently very low. Typical impingement processes use controlled drybulb temperatures (ambient temperature of an environment) of $175^{\circ} \mathrm{C}$ to $260^{\circ} \mathrm{C}$ and wet-bulb temperatures (temperature at which evaporation of water occurs) of $54^{\circ} \mathrm{C}$ to $96^{\circ} \mathrm{C}$. If an oven is running at a $204^{\circ} \mathrm{C}$ drybulb temperature and $82^{\circ} \mathrm{C}$ wet-bulb temperature, for example, the relative humidity inside the oven is calculated to be $2.8 \%$. If impingement ovens are run under ambient conditions without humidity control, the wetbulb temperature generally drifts between $49^{\circ} \mathrm{C}$ and $66^{\circ} \mathrm{C}$, depending on the naturally available moisture from the surrounding air and the moisture evaporated from the product. In most impingement ovens, however, steam injection is used to control the wet-bulb temperature between $71^{\circ} \mathrm{C}$ and $96^{\circ} \mathrm{C}$. Although the theoretically highest achievable wet-bulb temperature at standard atmospheric pressure would be the $100^{\circ} \mathrm{C}$ boiling point of water, the practical maximum in most impingement ovens is typically $93^{\circ} \mathrm{C}$ to $96^{\circ} \mathrm{C}$.

Most published pathogen lethality studies use inoculated samples that have a high water activity (i.e., $a_{w}$ at $>0.97$ ) to measure the D- and z-values. In these studies, the inoculated meat samples are usually packaged in moisture-impermeable plastic film and then immersed in hot water for heating (O'Bryan et al., 2006; McMinn et al., 2018). As such, these experiments seldom account for the increased heat tolerance of desiccated pathogens resulting from surface dehydration that often occurs when products are cooked in forcedair convection ovens. In industrial cooking processes, then, only meat products cooked under hydrated conditions can reliably use the literature values as references. Researchers have found that heat tolerances for Salmonella are much higher when it is desiccated than when hydrated (Goodfellow and Brown, 1978; Burnett, et al., 2000; Jay et al., 2005; Buege et al., 2006; Gruzdev et al., 2011; Sindelar et al., 2016). Gruzdev et al. (2011) also found, however, that if desiccated Salmonella enterica were rehydrated, the heat tolerance was similar to that of Salmonella that had never been desiccated. Goodfellow and Brown (1978) and Buege et al. (2006) also found that rehydration heating steps were effective in eliminating desiccated Salmonella from meat surfaces. Therefore, a comprehensive investigation of the heat tolerance and survival of Salmonella on product surfaces during cooking in high-temperature, short-duration impingement oven processes is warranted to develop more reliable methods for ensuring sufficient reductions of Salmonella.

Cooking meat products in forced-air convection ovens such as impingement ovens is essentially a high-temperature drying process (Skjöldebrand, 1980). Based on previous research regarding drying phases during cooking, we hypothesized that during the wet-surface phases of a cooking process-the preheat and constant-rate drying periods-the inoculated Salmonella on the product surfaces would be fully hydrated and thus be susceptible to the standard D- and z-values from the literature for hydrated Salmonella (O'Bryan et al., 2006; McMinn et al., 2018). To test this hypothesis, we designed thermal processes for this study that used hydrated surface 
lethality (HSL) steps that exposed the product surfaces to lethal time-temperature conditions during the saturated-surface, constant-rate drying period. We further hypothesized that if during cooking the surface transitioned from the wet-surface constant-rate drying period to the dry-surface falling-rate period before sufficient reduction of Salmonella was achieved, the surface dehydration that occurred during the fallingrate drying period would increase the proportion of desiccated, heat-tolerant Salmonella, thus increasing the likelihood that significant populations of heattolerant Salmonella would survive (Sindelar et al., 2016). To test this hypothesis, we designed thermal processes for this study that used dry heat for part or all of the thermal processes to measure the effects of surface dehydration on survival rates of surfaceinoculated Salmonella. Finally, we hypothesized that if surface dehydration occurred early in the thermal process, subsequent HSL steps could be used to rehydrate the dry surfaces at lethal temperatures to provide sufficient lethality for any desiccated pathogens. To test this hypothesis, we designed heat processes that rapidly dried the surfaces early in the process using dry heat and then used subsequent HSL steps to condense moisture on the product surfaces at lethal temperatures later in the process. This process design was based on the findings of Gruzdev et al. (2011) that desiccated Salmonella enterica that were later rehydrated were as susceptible to heat as the original nondesiccated Salmonella.

The objectives of this study were to (1) assess the survival of surface-inoculated Salmonella on products cooked using impingement cooking processes under hydrating and dehydrating conditions; (2) determine the effectiveness of HSL steps for countering the increased heat tolerance of desiccated Salmonella; and (3) develop scientific-based, regulatory-supported, and industry-useful thermal processing parameters for validating pathogen destruction and regulatory compliance for meat products cooked using impingement ovens.

\section{Materials and Methods}

\section{Development of the hydrated surface lethality method}

An HSL method was developed with the aim of effectively eliminating Salmonella that may be present on the product surfaces. To qualify as an HSL step, the heat step needed to ensure that the product surface was heated to a lethal time-temperature combination for the target pathogen and that the surface was fully hydrated when these lethal time-temperature conditions were achieved. To meet these criteria, the product surfaces needed to be heated to a lethal time-temperature combination before the surface dried out so that the HSL step inactivated the target pathogen before desiccation occurred. However, if the product surfaces dried out before thermally lethal conditions were achieved, the HSL criteria could still be met if the dried surfaces were rehydrated and then exposed to lethal timetemperature conditions while still hydrated.

\section{Experimental design for treatments}

Seven products were selected to represent the common commercially available range of meat species, fat levels, product types, and product dimensions. Chicken tenders were cut from boneless chicken breasts $(<3 \%$ fat). Six ground meat products were manufactured using 3 species (beef, pork, and chicken) with 2 different fat levels for each species (10\% and $30 \%$ for beef and pork; $10 \%$ and $20 \%$ for chicken) (Tables 1-2). Raw meats were surface inoculated with a 5-strain mixture of Salmonella (described as follows) and thermally processed in a two-zone impingement oven (upper and lower ovens). Seven different cooking processes were used to cook the products using predetermined total cooking times of $3.0 \mathrm{~min}$ for processes using HSL steps in both zones, $3.5 \mathrm{~min}$ for processes using an HSL step in only one zone, or 4.0 min for dry cooking processes not using HSL steps

Table 1. Product formulations for manufacture of chicken tenders, beef patties, pork patties, and chicken patties ${ }^{\mathrm{a}}$.

\begin{tabular}{|c|c|c|c|c|c|c|c|}
\hline \multirow[b]{3}{*}{ Non-Meat Ingredient } & \multicolumn{7}{|c|}{ Product } \\
\hline & \multirow{2}{*}{$\frac{\text { Chicken Tenders }}{\leq 3 \% \text { Fat }}$} & \multicolumn{2}{|c|}{ Beef Patties } & \multicolumn{2}{|c|}{ Pork Patties } & \multicolumn{2}{|c|}{ Chicken Patties } \\
\hline & & $10 \%$ Fat & $30 \%$ Fat & $10 \%$ Fat & $30 \%$ Fat & $10 \%$ Fat & $20 \%$ Fat \\
\hline Water & 5.00 & 0.00 & 0.00 & 2.00 & 2.00 & 2.00 & 2.00 \\
\hline Salt & 2.50 & 0.00 & 0.00 & 2.50 & 2.50 & 2.50 & 2.50 \\
\hline Sodium tripolyphosphate (STPP) & 0.35 & 0.00 & 0.00 & 0.35 & 0.35 & 0.35 & 0.35 \\
\hline
\end{tabular}

${ }^{\text {a}}$ Formulated ingredients reported as ingoing percentage on a raw meat weight basis. 
Table 2. Physiochemical properties ${ }^{\mathrm{a}}$ of raw chicken tenders, beef patties, pork patties, and chicken patties.

\begin{tabular}{lcrrrr}
\hline \hline Product & \% Moisture & \multicolumn{1}{c}{ \% Fat ${ }^{\mathrm{c}}$} & \% NaCl & \multicolumn{1}{c}{$\mathrm{pH}^{\mathrm{e}}$} \\
\hline Chicken Tenders - 3\% Fat & $76.1 \pm 0.92$ & $2.6 \pm 0.29$ & $2.4 \pm 0.05$ & $6.41 \pm 0.08$ & $0.979 \pm 0.001$ \\
Beef Patties - 10\% Fat & $69.0 \pm 0.39$ & $10.4 \pm 0.31$ & $0.2 \pm 0.02$ & $5.88 \pm 0.07$ & $0.986 \pm 0.001$ \\
Beef Patties - 30\% Fat & $51.4 \pm 0.33$ & $30.6 \pm 0.85$ & $0.2 \pm 0.06$ & $5.94 \pm 0.01$ & $0.983 \pm 0.001$ \\
Pork Patties - 10\% Fat & $71.1 \pm 0.62$ & $10.4 \pm 0.72$ & $2.5 \pm 0.11$ & $6.22 \pm 0.01$ & $0.976 \pm 0.001$ \\
Pork Patties - 30\% Fat & $52.9 \pm 0.36$ & $29.5 \pm 0.83$ & $2.4 \pm 0.08$ & $6.29 \pm 0.01$ & $0.974 \pm 0.001$ \\
Chicken Patties - 10\% Fat & $72.0 \pm 0.37$ & $9.7 \pm 0.60$ & $2.4 \pm 0.23$ & $6.41 \pm 0.03$ & $0.979 \pm 0.001$ \\
Chicken Patties - 20\% Fat & $62.6 \pm 0.83$ & $19.1 \pm 0.49$ & $2.6 \pm 0.03$ & $6.52 \pm 0.00$ & $0.977 \pm 0.001$ \\
\hline
\end{tabular}

${ }^{a}$ Values expressed as mean \pm standard deviation from all replications ( $n=9$ for chicken tenders; $n=3$ for other products). For chicken tenders, triplicate samples from each replication were analyzed for physiochemical properties. The beef, pork, and chicken patties used meat from a single batch for all three replications. Triplicate samples from each batch were analyzed for physiochemical properties.

${ }^{b}$ Vacuum oven method, $5 \mathrm{~h}, 100^{\circ} \mathrm{C}$; Association of Official Analytical Chemists, method 950.46.

${ }^{\mathrm{c}}$ Microwave and nuclear magnetic resonance method; CEM SMART Turbo Moisture/Solid Analyzer; Association of Official Analytical Chemists, method 2008.06

${ }^{\mathrm{d}}$ Measured as $\% \mathrm{Cl}^{-}, \mathrm{AgNO}_{3}$ potentiometric titration, Mettler $\mathrm{G} 20$ compact titrator.

e Indirect $\mathrm{pH}$ by using an Accumet Basic $\mathrm{pH}$ meter with an Orion 8104 combination electrode, $10 \mathrm{~g}$ of meat and $90 \mathrm{ml}$ of distilled water.

${ }_{\mathrm{f}}$ Measured using a Decagon Aqua lab 4TE water activity meter

Table 3. Cook process parameters ${ }^{\mathrm{a}}$ and least square means for reductions of Salmonella ${ }^{\mathrm{b}}$ on the surface of chicken tenders.

\begin{tabular}{|c|c|c|c|c|c|c|c|c|c|c|}
\hline \multirow[b]{4}{*}{ Process } & \multicolumn{7}{|c|}{ Process Parameters } & \multirow{2}{*}{\multicolumn{3}{|c|}{$\begin{array}{l}\text { Total Salmonella } \\
\text { reduction }\end{array}$}} \\
\hline & \multicolumn{3}{|c|}{ Zone 1} & \multicolumn{3}{|c|}{ Zone 2} & \multirow{3}{*}{$\begin{array}{c}\text { Total Time } \\
\text { mm:ss }\end{array}$} & & & \\
\hline & \multirow{2}{*}{$\begin{array}{c}\text { Dry Bulb } \\
\left({ }^{\circ} \mathrm{C}\right) \\
\end{array}$} & \multirow{2}{*}{$\begin{array}{c}\text { Wet Bulb } \\
\left({ }^{\circ} \mathrm{C}\right)\end{array}$} & \multirow{2}{*}{$\begin{array}{c}\text { Time } \\
\text { mm:ss }\end{array}$} & \multirow{2}{*}{$\begin{array}{c}\text { Dry Bulb } \\
\left({ }^{\circ} \mathrm{C}\right) \\
\end{array}$} & \multirow{2}{*}{$\begin{array}{c}\text { Wet Bulb } \\
\left({ }^{\circ} \mathrm{C}\right) \\
\end{array}$} & \multirow{2}{*}{$\begin{array}{c}\text { Time } \\
\text { mm:ss }\end{array}$} & & & $\%$ & \\
\hline & & & & & & & & $\log$ & \pm & S.E. \\
\hline 1 & 204.4 & ambient & $2: 00$ & 204.4 & ambient & $2: 00$ & $4: 00$ & $4.02^{z}$ & \pm & 0.64 \\
\hline 2 & 204.4 & 71.1 & $1: 30$ & 204.4 & 71.1 & $1: 30$ & $3: 00$ & $6.93^{\mathrm{y}}$ & \pm & 0.49 \\
\hline 3 & 204.4 & 71.1 & $1: 30$ & 204.4 & ambient & $2: 00$ & $3: 30$ & $7.22^{\mathrm{y}}$ & \pm & 0.47 \\
\hline 4 & 204.4 & ambient & $2: 00$ & 204.4 & 71.1 & $1: 30$ & $3: 30$ & $3.52^{\mathrm{z}}$ & \pm & 0.17 \\
\hline 5 & 204.4 & ambient & $2: 00$ & 204.4 & 82.2 & $1: 30$ & $3: 30$ & $6.91^{\mathrm{y}}$ & \pm & 0.45 \\
\hline 6 & 204.4 & 82.2 & $1: 30$ & 204.4 & ambient & $2: 00$ & $3: 30$ & $6.94^{\mathrm{y}}$ & \pm & 0.35 \\
\hline 7 & 204.4 & 82.2 & $1: 30$ & 204.4 & 82.2 & $1: 30$ & $3: 00$ & $7.20^{\mathrm{y}}$ & \pm & 0.20 \\
\hline
\end{tabular}

aProducts were cooked in two XLT conveyor ovens (Model 1832-01596) modified to allow for steam injection. Each zone refers to passage through a single oven. For processes where both zones had identical parameters, products were passed through the same oven twice.

${ }^{\mathrm{b}}$ Salmonella reductions shown are the mean of three replicate experiments and expressed as mean \pm standard error. The inoculated average was 8.14 log $\mathrm{CFU} / \mathrm{g} \pm 0.23$.

${ }^{\mathrm{y}, \mathrm{z}}$ Means within a product and fat level with unlike superscript letters are significantly different $(\mathrm{P}<0.05)$.

(Tables 3-6). Steam injection was used to control the wet-bulb temperature as required for the HSL processes. The fixed cooking times were used for each process category to ensure that each product was exposed to the same conditions for the same treatment time within each process category. Preliminary trials were conducted to ensure that when the products were cooked using these processes and times, the surface temperatures exceeded $71.1^{\circ} \mathrm{C}$ at the end of the cooking processes. Triplicate samples were assayed for Salmonella populations prior to cook (Time 0), between the two zones (Midpoint), and after the full cook (Endpoint).
Each set of experiments was replicated 3 times. A replication was defined as the cooking of samples for a single product using all 7 cooking processes in the same day.

\section{Product manufacture}

The 7 products representing a range of meat species, fat levels, and product types were manufactured to be representative of commercially available products. Product dimensions were based on measurements of similar commercially available products and input 
Table 4. Cook process parameters ${ }^{\mathrm{a}}$ and least square means for reductions of Salmonella ${ }^{\mathrm{b}}$ on the surface of ground beef patties with either $10 \%$ or $30 \%$ fat.

\begin{tabular}{|c|c|c|c|c|c|c|c|c|c|c|c|c|c|}
\hline \multirow[b]{4}{*}{ Process } & \multicolumn{7}{|c|}{ Process Parameters } & & & & & & \\
\hline & \multicolumn{3}{|c|}{ Zone 1} & \multicolumn{3}{|c|}{ Zone 2} & \multirow{3}{*}{$\begin{array}{c}\text { Total Time } \\
\mathrm{mm}: \mathrm{ss} \\
\end{array}$} & \multicolumn{6}{|c|}{ Total Salmonella reduction } \\
\hline & \multirow{2}{*}{$\begin{array}{c}\text { Dry Bulb } \\
\left({ }^{\circ} \mathrm{C}\right)\end{array}$} & \multirow{2}{*}{$\begin{array}{c}\text { Wet Bulb } \\
\left({ }^{\circ} \mathrm{C}\right)\end{array}$} & \multirow{2}{*}{$\begin{array}{l}\text { Time } \\
\text { mm:ss }\end{array}$} & \multirow{2}{*}{$\begin{array}{c}\text { Dry Bulb } \\
\left({ }^{\circ} \mathrm{C}\right)\end{array}$} & \multirow{2}{*}{$\begin{array}{c}\text { Wet Bulb } \\
\left({ }^{\circ} \mathrm{C}\right)\end{array}$} & \multirow{2}{*}{$\begin{array}{l}\text { Time } \\
\text { mm:ss }\end{array}$} & & \multicolumn{3}{|c|}{$10 \%$ fat } & \multicolumn{3}{|c|}{$30 \%$ fat } \\
\hline & & & & & & & & $\log$ & \pm & S.E. & $\log$ & \pm & S.E. \\
\hline 1 & 204.4 & ambient & 2:00 & 204.4 & ambient & 2:00 & 4:00 & $6.19^{\mathrm{z}}$ & \pm & 0.46 & $7.03^{\mathrm{yz}}$ & \pm & 0.49 \\
\hline 2 & 204.4 & 71.1 & $1: 30$ & 204.4 & 71.1 & $1: 30$ & $3: 00$ & $7.15^{z}$ & \pm & 0.38 & $6.69^{\mathrm{z}}$ & \pm & 0.12 \\
\hline 3 & 204.4 & 71.1 & $1: 30$ & 204.4 & ambient & 2:00 & $3: 30$ & $6.89^{\mathrm{z}}$ & \pm & 0.42 & $7.19^{\mathrm{yz}}$ & \pm & 0.37 \\
\hline 4 & 204.4 & ambient & 2:00 & 204.4 & 71.1 & $1: 30$ & $3: 30$ & $7.38^{\mathrm{z}}$ & \pm & 0.85 & $7.86^{\mathrm{yz}}$ & \pm & 0.36 \\
\hline 5 & 204.4 & ambient & $2: 00$ & 204.4 & 82.2 & $1: 30$ & $3: 30$ & $7.74^{\mathrm{z}}$ & \pm & 0.48 & $7.82^{\mathrm{yz}}$ & \pm & 0.41 \\
\hline 6 & 204.4 & 82.2 & $1: 30$ & 204.4 & ambient & $2: 00$ & $3: 30$ & $7.01^{z}$ & \pm & 0.55 & $7.37^{\mathrm{yz}}$ & \pm & 0.75 \\
\hline 7 & 204.4 & 82.2 & $1: 30$ & 204.4 & 82.2 & $1: 30$ & 3:00 & $7.87^{z}$ & \pm & 0.22 & $7.97^{\mathrm{y}}$ & \pm & 0.25 \\
\hline
\end{tabular}

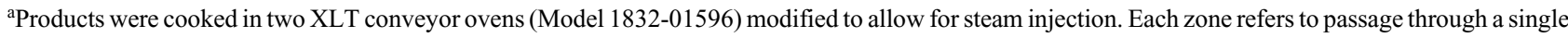
oven. For processes where both zones had identical parameters, products were passed through the same oven twice.

${ }^{\mathrm{b}}$ Salmonella reductions shown are the mean of three replicate experiments and expressed as mean \pm standard error. The inoculated average was 8.34 log $\mathrm{CFU} / \mathrm{g} \pm 0.29$ (10\% fat) and $8.52 \log \mathrm{CFU} / \mathrm{g} \pm 0.12$ (30\% fat).

$\mathrm{y}, \mathrm{z}$ Means within a product and fat level with unlike superscript letters are different $(\mathrm{P}<0.05)$.

Table 5. Cook process parameters ${ }^{\mathrm{a}}$ and least square means for reductions of Salmonella ${ }^{\mathrm{b}}$ on the surface of ground pork patties with either $10 \%$ or $30 \%$ fat.

\begin{tabular}{|c|c|c|c|c|c|c|c|c|c|c|c|c|c|}
\hline \multirow[b]{4}{*}{ Process } & \multicolumn{7}{|c|}{ Process Parameters } & & & & & & \\
\hline & \multicolumn{3}{|c|}{ Zone 1} & \multicolumn{3}{|c|}{ Zone 2} & \multirow{3}{*}{$\begin{array}{c}\text { Total Time } \\
\text { mm:ss }\end{array}$} & \multicolumn{6}{|c|}{ Total Salmonella reduction } \\
\hline & \multirow{2}{*}{$\begin{array}{c}\text { Dry Bulb } \\
\left({ }^{\circ} \mathrm{C}\right)\end{array}$} & \multirow{2}{*}{$\begin{array}{c}\text { Wet Bulb } \\
\left({ }^{\circ} \mathrm{C}\right)\end{array}$} & \multirow{2}{*}{$\begin{array}{l}\text { Time } \\
\text { mm:ss }\end{array}$} & \multirow{2}{*}{$\begin{array}{c}\text { Dry Bulb } \\
\left({ }^{\circ} \mathrm{C}\right)\end{array}$} & \multirow{2}{*}{$\begin{array}{c}\text { Wet Bulb } \\
\left({ }^{\circ} \mathrm{C}\right)\end{array}$} & \multirow{2}{*}{$\begin{array}{l}\text { Time } \\
\text { mm:ss }\end{array}$} & & \multicolumn{3}{|c|}{$10 \%$ fat } & \multicolumn{3}{|c|}{$30 \%$ fat } \\
\hline & & & & & & & & $\log$ & \pm & S.E. & $\log$ & \pm & S.E. \\
\hline 1 & 204.4 & ambient & $2: 00$ & 204.4 & ambient & $2: 00$ & 4:00 & $5.78^{\mathrm{z}}$ & \pm & 0.39 & $7.05^{\mathrm{z}}$ & \pm & 0.05 \\
\hline 2 & 204.4 & 71.1 & $1: 30$ & 204.4 & 71.1 & $1: 30$ & 3:00 & $7.97^{x}$ & \pm & 0.13 & $7.89^{\mathrm{yz}}$ & \pm & 0.25 \\
\hline 3 & 204.4 & 71.1 & $1: 30$ & 204.4 & ambient & $2: 00$ & $3: 30$ & $7.31^{\mathrm{xyz}}$ & \pm & 0.24 & $7.56^{\mathrm{yz}}$ & \pm & 0.39 \\
\hline 4 & 204.4 & ambient & $2: 00$ & 204.4 & 71.1 & $1: 30$ & $3: 30$ & $7.01^{\mathrm{yz}}$ & \pm & 0.07 & $7.71^{\mathrm{yz}}$ & \pm & 0.40 \\
\hline 5 & 204.4 & ambient & $2: 00$ & 204.4 & 82.2 & $1: 30$ & $3: 30$ & $7.64^{x y}$ & \pm & 0.37 & $7.89^{\mathrm{yz}}$ & \pm & 0.47 \\
\hline 6 & 204.4 & 82.2 & $1: 30$ & 204.4 & ambient & $2: 00$ & $3: 30$ & $7.64^{x y}$ & \pm & 0.37 & $7.56^{\mathrm{yz}}$ & \pm & 0.39 \\
\hline 7 & 204.4 & 82.2 & $1: 30$ & 204.4 & 82.2 & $1: 30$ & $3: 00$ & $7.97^{\mathrm{x}}$ & \pm & 0.13 & $8.23^{y}$ & \pm & 0.14 \\
\hline
\end{tabular}

aProducts were cooked in two XLT conveyor ovens (Model 1832-01596) modified to allow for steam injection. Each zone refers to passage through a single oven. For processes where both zones had identical parameters, products were passed through the same oven twice.

${ }^{\mathrm{b}}$ Salmonella reductions shown are the mean of three replicate experiments and expressed as mean \pm standard error. The inoculated average was 8.27 log $\mathrm{CFU} / \mathrm{g} \pm 0.22$ (10\% fat) and $8.53 \log \mathrm{CFU} / \mathrm{g} \pm 0.25$ (30\% fat).

${ }^{\mathrm{xyz}}$ Means within a product and fat level with unlike superscript letters are different $(\mathrm{P}<0.05)$.

from processors regularly manufacturing these types of products. Ground meat products were formulated to represent practical worst-case scenarios for Salmonella survival. For example, previous studies have shown that high $\mathrm{pH}$ and high salt content enhance the heat tolerance of Salmonella (Kang and Fung, 2000; Juneja et al., 2003; van Asselt and Zwietering, 2006; Aljarallah and Adams, 2007). Therefore, the products containing salt and phosphate were intentionally formulated with salt and phosphate levels on the high side of typical industry formulas (Table 1). The ground pork and chicken patties contained $2.5 \%$ salt, $0.35 \%$ sodium tripolyphosphate, and $2.0 \%$ water. The ground beef patties contained no additional ingredients as is common industry practice. The whole-muscle chicken tenders ( $\leq 3 \%$ fat) were formulated with $2.5 \%$ salt, $0.35 \%$ sodium tripolyphosphate, and $5.0 \%$ water. All nonmeat ingredient additions were based on a raw-meat weight basis. Prior to inoculation, ground meat products were formed into patties and chilled overnight. The chicken tenders were hand cut to the appropriate size and chilled overnight to ensure all portions of the muscle were a consistent temperature after fabrication and prior to cooking.

Ground meat patties were manufactured using Good Manufacturing Practices at the University of 
Table 6. Cook process parameters ${ }^{\mathrm{a}}$ and least square means for reductions of Salmonella ${ }^{\mathrm{b}}$ on the surface of ground chicken patties with either $10 \%$ or $20 \%$ fat.

\begin{tabular}{|c|c|c|c|c|c|c|c|c|c|c|c|c|c|}
\hline \multirow[b]{4}{*}{ Process } & \multicolumn{7}{|c|}{ Process Parameters } & & & & & & \\
\hline & \multicolumn{3}{|c|}{ Zone 1} & \multicolumn{3}{|c|}{ Zone 2} & \multirow{3}{*}{$\begin{array}{c}\text { Total Time } \\
\text { mm:ss }\end{array}$} & \multicolumn{6}{|c|}{ Total Salmonella reduction } \\
\hline & \multirow{2}{*}{$\begin{array}{c}\text { Dry Bulb } \\
\left({ }^{\circ} \mathrm{C}\right)\end{array}$} & \multirow{2}{*}{$\begin{array}{c}\text { Wet Bulb } \\
\left({ }^{\circ} \mathrm{C}\right)\end{array}$} & \multirow{2}{*}{$\begin{array}{l}\text { Time } \\
\text { mm:ss }\end{array}$} & \multirow{2}{*}{$\begin{array}{c}\text { Dry Bulb } \\
\left({ }^{\circ} \mathrm{C}\right)\end{array}$} & \multirow{2}{*}{$\begin{array}{c}\text { Wet Bulb } \\
\left({ }^{\circ} \mathrm{C}\right)\end{array}$} & \multirow{2}{*}{$\begin{array}{l}\text { Time } \\
\text { mm:ss }\end{array}$} & & \multicolumn{3}{|c|}{$10 \%$ fat } & \multicolumn{3}{|c|}{$20 \%$ fat } \\
\hline & & & & & & & & $\log$ & \pm & S.E. & $\log$ & \pm & S.E. \\
\hline 1 & 204.4 & ambient & $2: 00$ & 204.4 & ambient & $2: 00$ & 4:00 & $6.33^{\mathrm{z}}$ & \pm & 0.70 & $6.79^{\mathrm{z}}$ & \pm & 0.55 \\
\hline 2 & 204.4 & 71.1 & $1: 30$ & 204.4 & 71.1 & $1: 30$ & $3: 00$ & $8.80^{\mathrm{y}}$ & \pm & 0.11 & $8.67^{\mathrm{z}}$ & \pm & 0.11 \\
\hline 3 & 204.4 & 71.1 & $1: 30$ & 204.4 & ambient & $2: 00$ & $3: 30$ & $8.30^{\mathrm{yz}}$ & \pm & 0.40 & $8.67^{\mathrm{z}}$ & \pm & 0.11 \\
\hline 4 & 204.4 & ambient & $2: 00$ & 204.4 & 71.1 & $1: 30$ & $3: 30$ & $8.39^{\mathrm{yz}}$ & \pm & 0.27 & $8.12^{\mathrm{z}}$ & \pm & 0.41 \\
\hline 5 & 204.4 & ambient & $2: 00$ & 204.4 & 82.2 & $1: 30$ & $3: 30$ & $8.76^{\mathrm{y}}$ & \pm & 0.10 & $8.67^{\mathrm{z}}$ & \pm & 0.11 \\
\hline 6 & 204.4 & 82.2 & $1: 30$ & 204.4 & ambient & $2: 00$ & $3: 30$ & $7.67^{\mathrm{yz}}$ & \pm & 0.67 & $8.67^{\mathrm{z}}$ & \pm & 0.11 \\
\hline 7 & 204.4 & 82.2 & $1: 30$ & 204.4 & 180 & $1: 30$ & $3: 00$ & $8.76^{\mathrm{y}}$ & \pm & 0.10 & $8.67^{z}$ & \pm & 0.11 \\
\hline
\end{tabular}

aProducts were cooked in two XLT conveyor ovens (Model 1832-01596) modified to allow for steam injection. Each zone refers to passage through a single oven. For processes where both zones had identical parameters, products were passed through the same oven twice.

${ }^{\mathrm{b}}$ Salmonella reductions shown are the mean of three replicate experiments and expressed as mean \pm standard error. The inoculated average was 9.06 log $\mathrm{CFU} / \mathrm{g} \pm 0.17$ (10\% fat) and $8.88 \log \mathrm{CFU} / \mathrm{g} \pm 0.37$ (30\% fat).

$\mathrm{y}, \mathrm{z}$ Means within a product and fat level with unlike superscript letters are different $(\mathrm{P}<0.05)$.

Wisconsin-Madison Meat Science and Muscle Biology Laboratory. Raw materials were obtained from a commercial supplier and stored at $<4^{\circ} \mathrm{C}$ for $\leq 72 \mathrm{~h}$ prior to use to ensure all work could be completed for products with consistent composition and microbial quality for experimental blocking and replication purposes. Ground beef patties were manufactured using fresh beef knuckles and fresh, closely trimmed beef chuck muscles. Ground pork patties were manufactured using fresh, closely trimmed pork shoulder muscles and fresh pork trimmings ( $42 \%$ lean). Ground chicken patties were manufactured using fresh deboned chicken leg quarters and frozen chicken skins. The chicken skins were thawed for $24 \mathrm{~h}$ at $<4^{\circ} \mathrm{C}$ prior to use. For all ground products, lean and fat ingredients were first ground separately through a $19.05-\mathrm{mm}$ plate attached to a grinder (Model 4732, Hobart Corporation, Troy, OH). The fat content of a representative sample from each coarsely ground raw material was then determined using a CEM SMART Turbo Moisture/Solids Analyzer (CEM Corporation, Matthews, NC) using the microwave and nuclear magnetic resonance method (Jay et al., 2005; $\mathrm{AOAC}, 2008)$. The appropriate fat and lean ingredients were then combined to make products containing $10 \%$ and $30 \%$ fat for ground beef and ground pork and $10 \%$ and $20 \%$ fat for ground chicken (Tables 1-2). For the pork and chicken patties, the raw meat and nonmeat ingredients were combined in a plastic tub and mixed by hand for $2 \mathrm{~min}$. All meat mixtures were ground 3 times through a 4.8 grinder plate. After grinding, the final fat content of each product was confirmed using a CEM SMART Turbo Moisture/Solids Analyzer (CEM
Corporation). Finished products were then weighed in $2.0-\mathrm{kg}$ portions and placed into oxygen- and moistureimpermeable bags (3-mil high-barrier pouches; oxygen transmission rate: 50 to $70 \mathrm{~cm}^{3} / \mathrm{m}^{2}, 24 \mathrm{~h}$ at $25^{\circ} \mathrm{C}$ and $60 \%$ relative humidity; water transmission rate: 6 to $7.5 \mathrm{~g} / \mathrm{m}^{2}, 24 \mathrm{~h}$ at $25^{\circ} \mathrm{C}$ and $90 \%$ relative humidity; UltraSource, Kansas City, MO), vacuum-sealed, and stored frozen at $<-20^{\circ} \mathrm{C}$ until use. Ground meat formulations were transported to the University of WisconsinMadison Food Research Institute and thawed at $<4.4^{\circ} \mathrm{C}$ for at least $24 \mathrm{~h}$ prior to testing. The meat was weighed into $70.0 \pm 2.0 \mathrm{~g}$ portions, compressed into $95.3-\mathrm{mm}$ diameter $\times 7.62-\mathrm{mm}$-thick patties using a custom-made patty press, and placed onto metal trays lined with nonstick aluminum foil. The samples were then held at $<4^{\circ} \mathrm{C}$ overnight, using plastic wrap to prevent excessive moisture loss during storage. All trials for the ground meat products were conducted using meat from a single batch of manufactured product.

Chicken tenders were manufactured using Good Manufacturing Practices at the University of Wisconsin-Madison Food Research Institute. Boneless, skinless chicken breasts ( $<3.0 \%$ fat) were obtained frozen from a commercial supplier and stored frozen at $<-20^{\circ} \mathrm{C}$ until use. The frozen chicken breasts were thawed for $24 \mathrm{~h}$ at $<4.4^{\circ} \mathrm{C}$. External fat was removed. Tenders were cut from the chicken breasts to target dimensions of $140.0 \mathrm{~mm}$ long $\times 36.8 \mathrm{~mm}$ wide $\times$ $11.4 \mathrm{~mm}$ thick to be representative of a typical commercial product. The tenders were combined with all nonmeat ingredients and mixed by hand for $5 \mathrm{~min}$ (Table 1). The tenders were then vacuum packaged in 
an oxygen- and moisture-impermeable bag, vacuum sealed, and stored at $<4^{\circ} \mathrm{C}$ for $24 \mathrm{~h}$ to allow additional absorption of nonmeat ingredients. After $24 \mathrm{~h}$, the tenders were removed from the package and weighed individually. To minimize variation in heating rate between samples, only tenders weighing $40.0 \pm 2.0 \mathrm{~g}$ were used for inoculated testing and temperature data collection. The tenders were then transferred to a fresh vacuum bag, vacuum sealed, and stored at $<4^{\circ} \mathrm{C}$ prior to testing. New lots of chicken tenders were manufactured prior to each cooking trial.

\section{Proximate and chemical analysis}

Triplicate, uninoculated raw samples from each product replication were assayed for physiochemical properties including moisture $\left(5 \mathrm{~h}, 100^{\circ} \mathrm{C}\right.$ vacuum oven method; AOAC, 2008), sodium chloride (measured as percentage chloride, silver nitrate potentiometric titration; Mettler G20 compact titrator, Mettler-Toledo, Columbus, $\mathrm{OH}$ ), water activity (Decagon AquaLab 4TE water activity meter; Meter Group Inc., Pullman, WA), and fat content (microwave and nuclear magnetic resonance method [AOAC, 2008] with CEM SMART Turbo Moisture/Solids Analyzer; CEM Corporation) (Leffler, et al., 2008). In addition, the $\mathrm{pH}$ (Accumet Basic $\mathrm{pH}$ meter and Orion 8104 combination electrode, Thermo Fisher Scientific, Waltham, MA) of the raw product was measured using a slurry obtained by removing a representative $10 \mathrm{~g}$ of the noninoculated sample and homogenizing it with $90 \mathrm{~mL}$ deionized water using a lab blender (Stomacher 400, Seward, West Sussex, UK). Results are reported in Table 2.

\section{Strain selection and inoculum preparation}

Five strains of Salmonella spp. (Enteritidis 6424, phage type 4, baked cheesecake isolate; Enteritidis E40, chicken ovary isolate; Heidelberg S13, clinical isolate; Typhimurium S9, clinical isolate; and Typhimurium M-09-0001-A1, peanut butter isolate) were used in this study. All strains were from the University of Wisconsin-Madison Food Research Institute stock culture collection. Strains were grown individually in $9 \mathrm{~mL}$ of Trypticase Soy Broth (Difco, BD Biosciences, Sparks Glencoe, MD) for 18 to $24 \mathrm{~h}$ at $37^{\circ} \mathrm{C}$. For each strain, $0.2-\mathrm{mL}$ aliquots of overnight culture were spread onto 4 trypticase soy agar (TSA) plates (BD Biosciences) and incubated at $37^{\circ} \mathrm{C}$ for 18 to $22 \mathrm{~h}$. Cells were harvested by scraping the surface of the TSA plates with a sterile inoculating loop and suspending in $4.5 \mathrm{~mL}$ of phosphate-buffered saline (PBS; pH 7.2). Equivalent populations of each strain were then combined and diluted to $50 \mathrm{~mL}$ with PBS to provide a mixture with a concentration of approximately $10 \log$ colony-forming units $(\mathrm{CFU}) / \mathrm{mL}$, with target $8 \log \mathrm{CFU} / \mathrm{g}$ inoculum for each product. Populations and purity of each strain and the mixture were verified by plating on TSA and xylose-lysinedeoxycholate agar (BD Biosciences). The plates were incubated at $37^{\circ} \mathrm{C}$ for 36 to $48 \mathrm{~h}$ prior to counting.

\section{Inoculation}

Immediately prior to inoculation, product samples were transferred from $<4^{\circ} \mathrm{C}$ storage to individual polystyrene trays sanitized with $70 \%$ ethyl alcohol. Samples were inoculated to $\sim 8 \log \mathrm{CFU} / \mathrm{g}$ with the 5strain Salmonella mixture using a $1.0 \%$ inoculum $(\mathrm{v} / \mathrm{w})$. The inoculum was spotted onto the upward-facing surface of each sample and spread evenly over the entire surface using the side of a sterile pipette. Trays containing the inoculated samples were then covered with a second polystyrene tray to prevent drying of the product surface. The inoculated samples were stored at $<4^{\circ} \mathrm{C}$ for at least $1 \mathrm{~h}$ before cooking to create a consistent internal temperature across all samples, but all samples were processed within $\leq 4 \mathrm{~h}$ after inoculation. Individual strains and the cocktail of the Salmonella used were enumerated to confirm viability and purity of the inoculum and were compared with the Time 0 (precook) samples to identify recovery from the inoculated product. The log reduction was calculated using the average populations of Salmonella recovered from triplicate uncooked, inoculated samples.

\section{Cooking}

Products were cooked in a two-zone continuous belt-fed impingement oven (Model 1832-01596 conveyor ovens, XLT Ovens, Wichita, KS) equipped with steam injection for controlling the wet-bulb temperature in each zone (Powis Corporation, Blue Springs, MO; Sindelar et al., 2020). The cooking procedure consisted of passing samples through both ovens, with the first oven designated as Zone 1 and the second oven designated as Zone 2 . The air velocity at the belt level for this oven was measured at 3.0 to $3.7 \mathrm{~m} / \mathrm{s}$. This air velocity is representative of common operational air velocities that would be expected at the conveyor belt level in production impingement ovens (R. E. Hanson, personal communication, 2018).

The 7 products were cooked using 7 different cooking processes (Processes 1-7) that were designed 
to assess the survival of surface-inoculated Salmonella using various combinations of dry-heat (ambient conditions) or steam-injected HSL steps (Tables 3-6). All processes used the same dry-bulb temperature of $204.4^{\circ} \mathrm{C}$. For the HSL steps, the wet-bulb temperature was controlled at either $71.1^{\circ} \mathrm{C}$ or $82.2^{\circ} \mathrm{C}$ using steam injection. The cooking times varied depending on the process category (dry-heat, one-zone HSL, or two-zone HSL) and were selected to ensure a product surface temperature $>71.1^{\circ} \mathrm{C}$ at the end of the process. The cooking time was 3.0 min for processes using HSL steps in both zones, $3.5 \mathrm{~min}$ for processes using an HSL step in only one zone, or $4.0 \mathrm{~min}$ for dry-heat cooking processes with no HSL steps. The focus of the experiment was to measure the effectiveness of the various processes on reductions of surfaceinoculated Salmonella when the surfaces were exposed to the process conditions for preset time periods, and therefore the process times were strictly controlled, but the surface and internal temperatures were not specifically controlled for each process.

Process 1 was a dry-heat, ambient-moisture process with no steam injection in either zone. This process was expected to dehydrate the product surfaces and create an increased proportion of desiccated Salmonella. Processes 2 and 7 had controlled wet-bulb temperature HSL steps using steam injection in both zones-the wet-bulb temperature was controlled at $71.1^{\circ} \mathrm{C}$ in both zones for Process 2 and $82.2^{\circ} \mathrm{C}$ in both zones for Process 7 . These 2 processes were intended to measure the effectiveness of controlled wet-bulb HSL steps that were applied for the entire cooking process using 2 different wet-bulb temperatures that were expected to be thermally lethal to Salmonella. Processes 3 and 6 were single-zone HSL process that used controlled wet-bulb HSL steps in Zone 1 followed by a dry-heat, ambient wet-bulb step in Zone 2. The wet-bulb temperature in Zone 1 was controlled at $71.1^{\circ} \mathrm{C}$ for Process 3 and $82.2^{\circ} \mathrm{C}$ for Process 6 . Processes 3 and 6 were intended to test whether a single-zone HSL process would provide sufficient lethality if the HSL step was applied in the first half of a process followed by a dry-heat, ambient wet-bulb step in Zone 2. Processes 4 and 5 were also single-zone HSL processes, but these processes instead applied the dry-heat, ambient wet-bulb step in the first zone followed by a controlled wet-bulb HSL step in Zone 2. The wet-bulb temperature in Zone 2 was controlled at $71.1^{\circ} \mathrm{C}$ for Process 4 and $82.2^{\circ} \mathrm{C}$ for Process 5. Processes 4 and 5 were intended to test whether a single-zone HSL process would provide sufficient lethality if the HSL step was applied in the second half of the process after a drying step in
Zone 1 that may have created desiccated, heat-tolerant Salmonella on the product surfaces.

\section{Sampling}

For each cooking process, 6 surface-inoculated Salmonella samples (patties or tenders) were taken from storage and placed onto 2 sanitized stainless-steel grates with the inoculated side facing up (triplicate samples/ grate). The grates were designed with openings large enough to allow sufficient airflow across all sides of the samples to simulate an impingement airflow oven (Sindelar et al., 2020). After the first grate had fully emerged from Zone 1, it was immediately transferred to the next conveyor belt and passed through Zone 2 . All 3 samples from the second grate were removed after exiting Zone 1 for enumeration as midpoint samples. After the remaining grate had fully emerged from Zone 2, all 3 samples from that grate were removed for enumeration as endpoint samples.

Samples were placed into sterile Whirl-Pak filter bags, diluted $1: 1$ with cold PBS $\left(\leq 4.4^{\circ} \mathrm{C}\right)$, and immediately submerged into an ice water bath for cooling. The chilled sample bags were hand massaged for approximately 2 min to release cells from the surface. Samples were enumerated for surviving Salmonella by plating serial dilutions onto xylose-lysine-deoxycholate overlaid with a thin layer of TSA to enhance recovery of injured cells (Mattick et al., 2000). Plates were incubated under aerobic conditions at $37^{\circ} \mathrm{C}$ for 36 to $48 \mathrm{~h}$ prior to counting.

\section{Temperature monitoring}

The dry-bulb, wet-bulb, product surface, and product internal temperatures were measured and recorded for each product and process combination following procedures described by Sindelar et al. (2020) to create thermal profiles (Figures 1-7). The oven and product temperatures were measured on test runs that were separate from the inoculation test runs. The thermal profiles were composited with data from a maximum of 7 calibrated data loggers (HiTemp140 single-point data logger, HiTemp140 X2 multichannel data logger; MadgeTech, Inc., Warner, $\mathrm{NH}$ ) that were recorded at 1-s intervals. The battery ends of data loggers were enclosed in protective Teflon heat-shield cases to prevent heat damage to the batteries and to maintain accuracy.

Three uninoculated samples were placed on a grate and passed through the impingement oven for collecting the oven and product temperature profiles. 


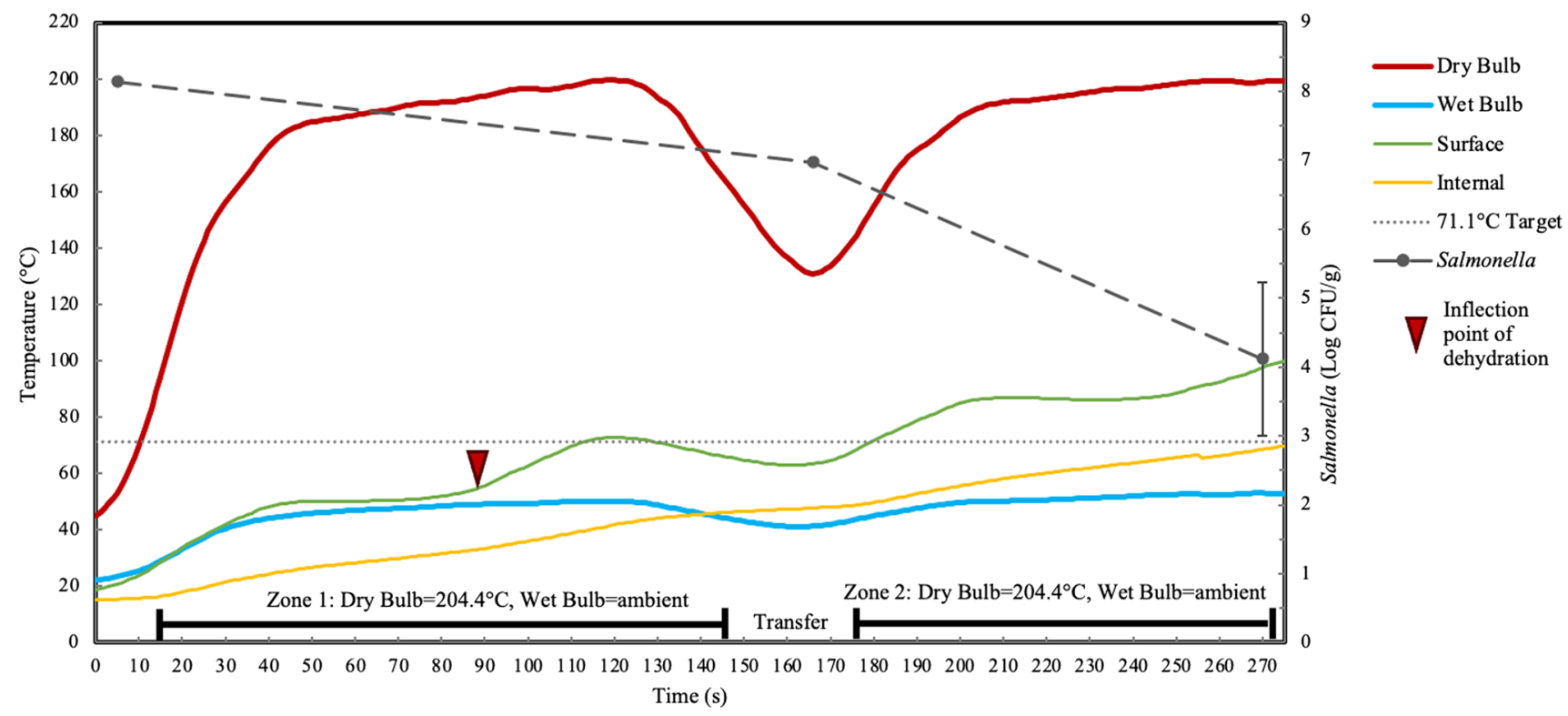

Figure 1. The ability for a two-zone dry-heat process (Process 1 , both zones = ambient wet bulb/dry heat) not including a hydrated surface lethality (HSL) to create time-temperature lethal and hydrated product surfaces for reducing surface-inoculated Salmonella on chicken tenders.

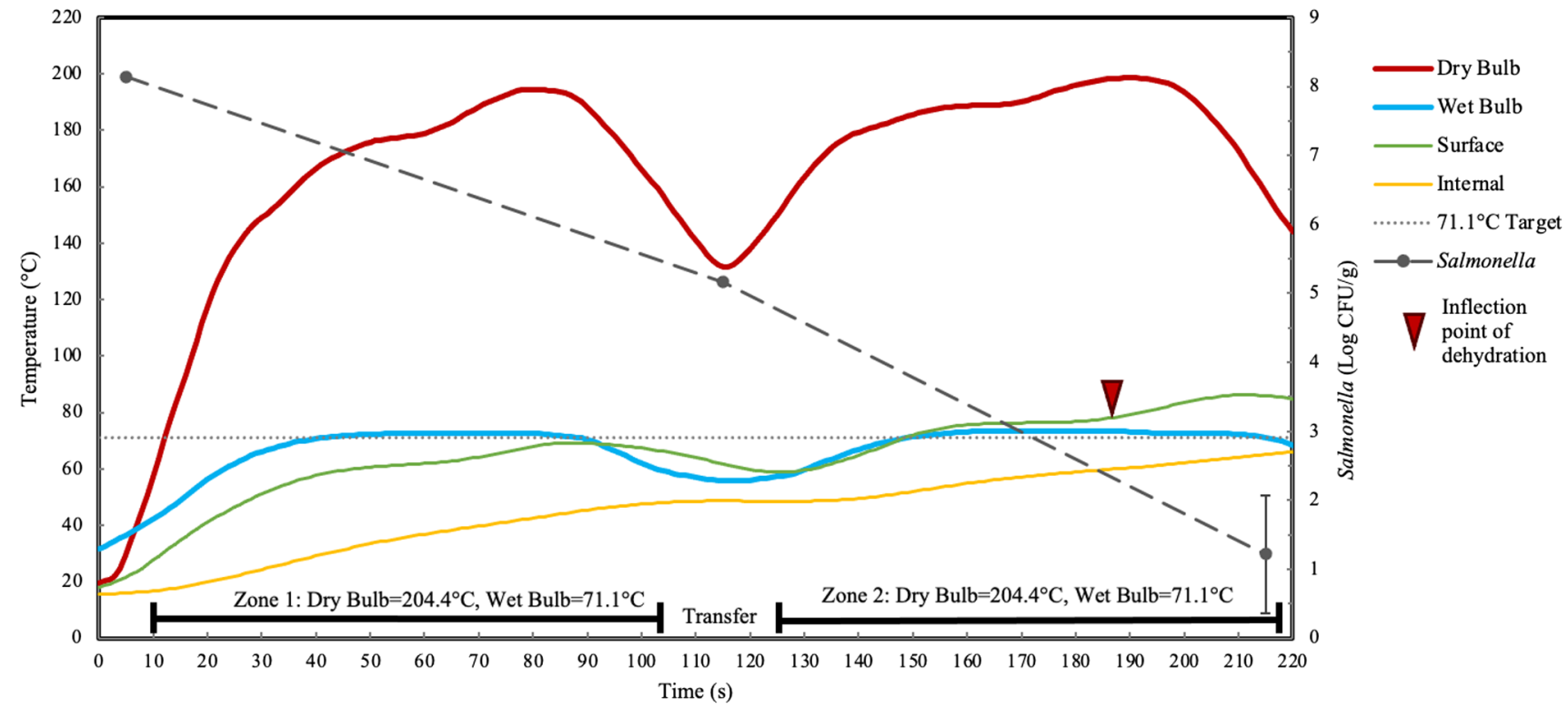

Figure 2. The ability for a two-zone hydrated surface lethality (HSL) process (Process $2,71.1^{\circ} \mathrm{C}$ wet bulb in both zones) to create time-temperature lethal and hydrated product surfaces for reducing surface-inoculated Salmonella on chicken tenders.

Single-channel loggers were used to measure the dryand wet-bulb temperature of the air and the surface and internal temperatures on 2 samples, whereas a dualchannel logger with 2 flexible probes was used to measure surface and internal temperatures on the third sample. The data loggers and samples were placed on 2 sanitized stainless-steel grates and passed through each zone concurrently to collect data for the thermal profiles. To measure the product surface temperature, a temperature probe was inserted approximately $25 \mathrm{~mm}$ into the product at a very shallow angle just under the surface so that the beveled sensing tip of the probe was just underneath and parallel to the surface. The surfacetemperature probes were positioned so that the sensing tip was just visible under a thin sheen of meat, making sure that the tip did not break through the surface. The temperature profiles for all figures are composite graphs of surface and internal temperatures from 3 test runs. If surface or internal temperatures from a single sample were found to be in error due to inadvertent movement of the probe, thermal profiles were compiled using data from the remaining 2 test runs. 


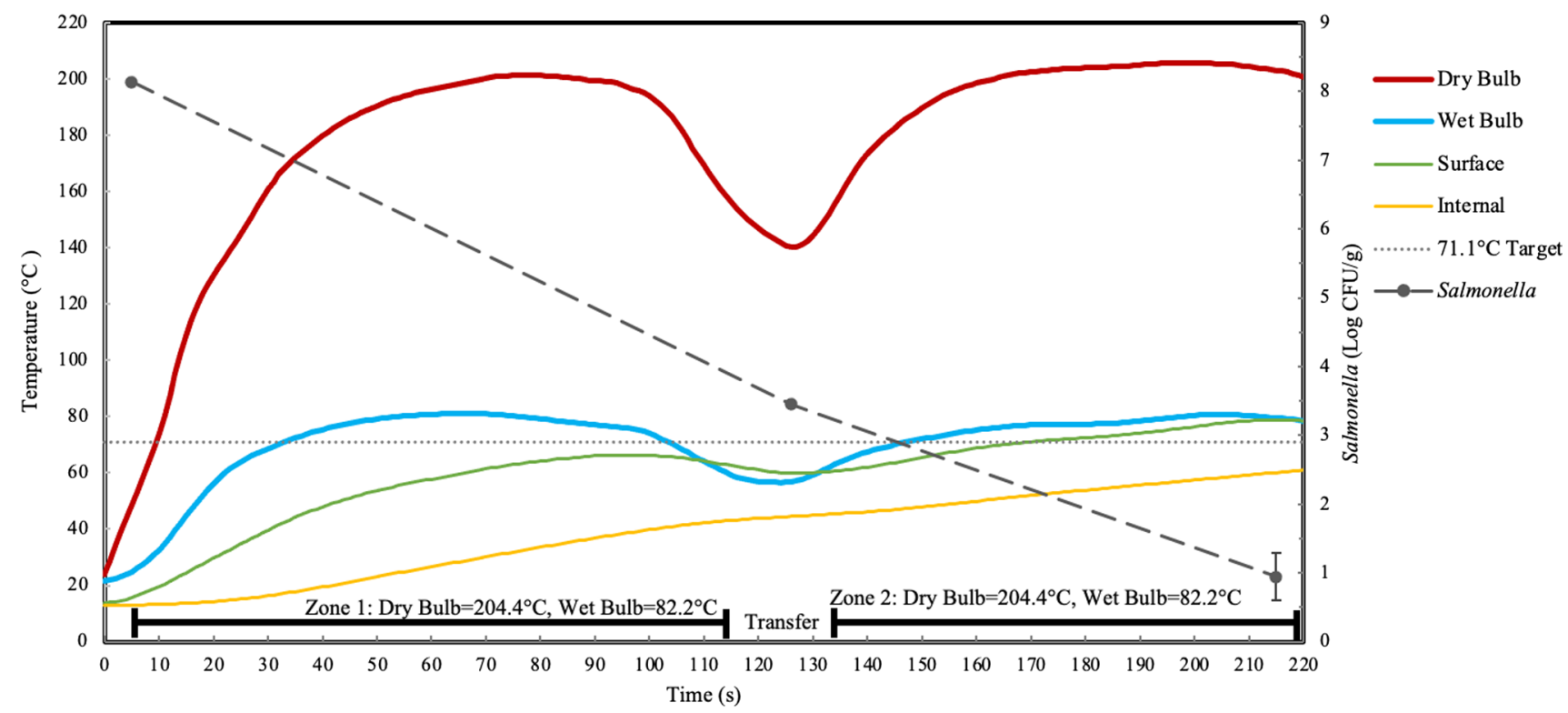

Figure 3. The ability for a two-zone hydrated surface lethality (HSL) process (Process $7,82.2^{\circ} \mathrm{C}$ wet bulb in both zones) to create time-temperature lethal and hydrated product surfaces for reducing surface-inoculated Salmonella on chicken tenders.

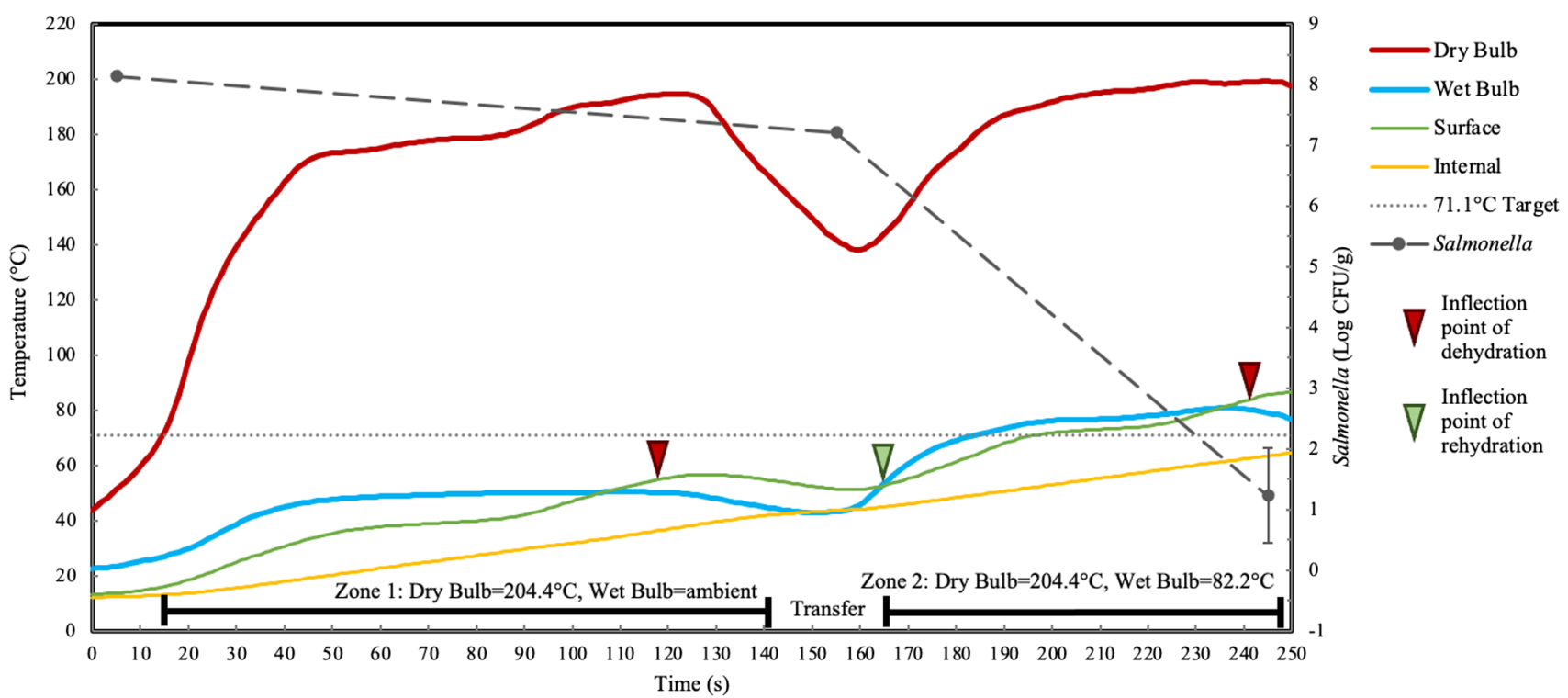

Figure 4. The ability for a single-zone hydrated surface lethality (HSL) process (Process $5,82.2^{\circ} \mathrm{C}$ wet bulb in second zone) to create time-temperature lethal and hydrated product surfaces for reducing surface-inoculated Salmonella on chicken tenders.

\section{Data analysis}

The microbiological data are average values and standard deviations (log CFU/gram) for triplicate samples per time point and 3 replications for each product-process combination. Log reduction was calculated by subtracting populations enumerated from individual midpoint or endpoint samples from the average Salmonella populations at Time 0 . The minimum detection limit was initially $1.3 \log \mathrm{CFU} / \mathrm{g}$ but then was reduced for later experiments to 1.0 or $0.3 \log \mathrm{CFU} / \mathrm{g}$ by increasing the volume of sample plated over a series of plates. The SAS MIXED procedure (SAS 9.1.3 Service Pack 3, SAS Institute Inc., Cary, NC) was used to determine significance $(P<0.05)$ between the endpoint Salmonella log reductions of the 7 processes within each product type using the Tukey-Kramer pairwise comparison method. When significance was found, means were separated using the difference of leastsquares means. Statistical comparisons are shown in letter assignment to individual means. 


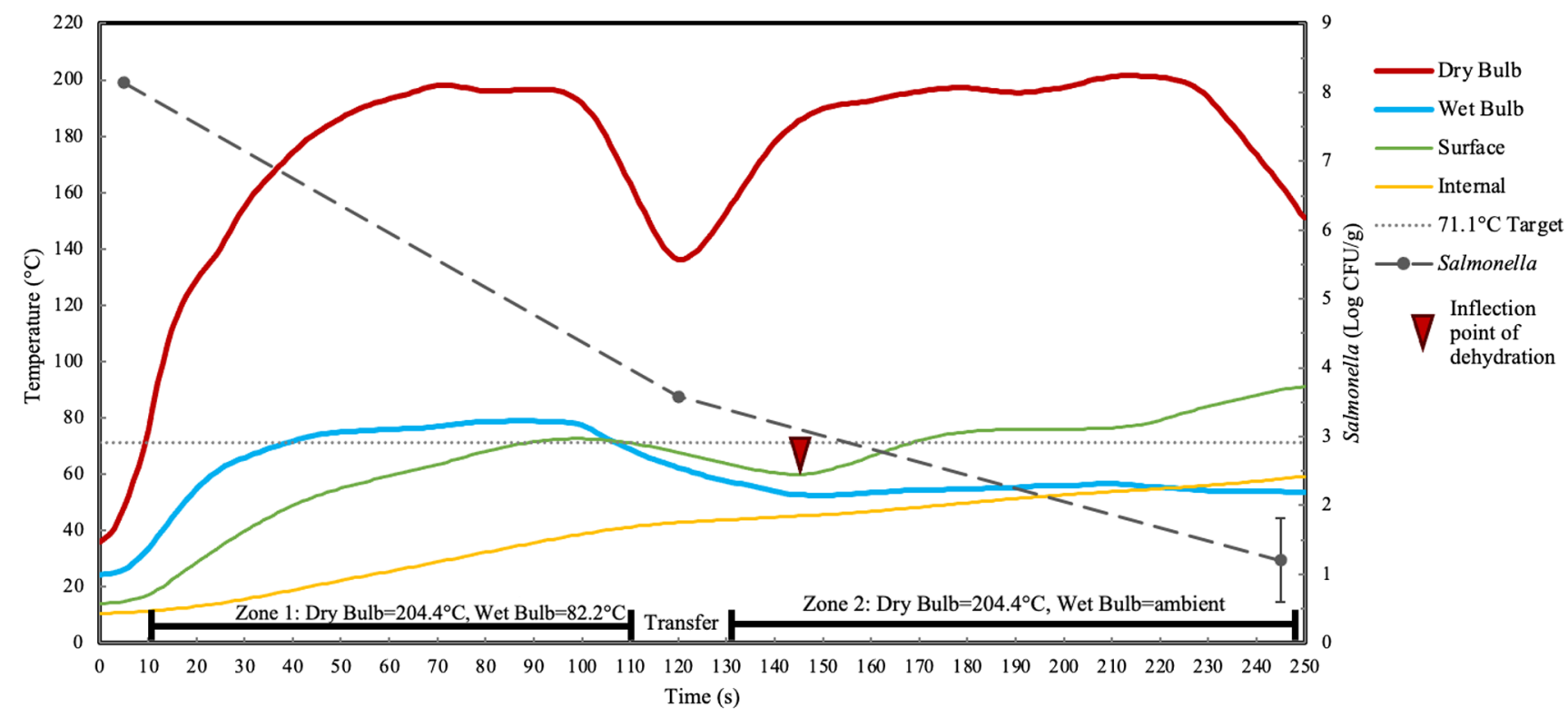

Figure 5. The ability for a single-zone hydrated surface lethality (HSL) process (Process $6,82.2^{\circ} \mathrm{C}$ wet bulb in first zone) to create time-temperature lethal and hydrated product surfaces for reducing surface-inoculated Salmonella on chicken tenders.

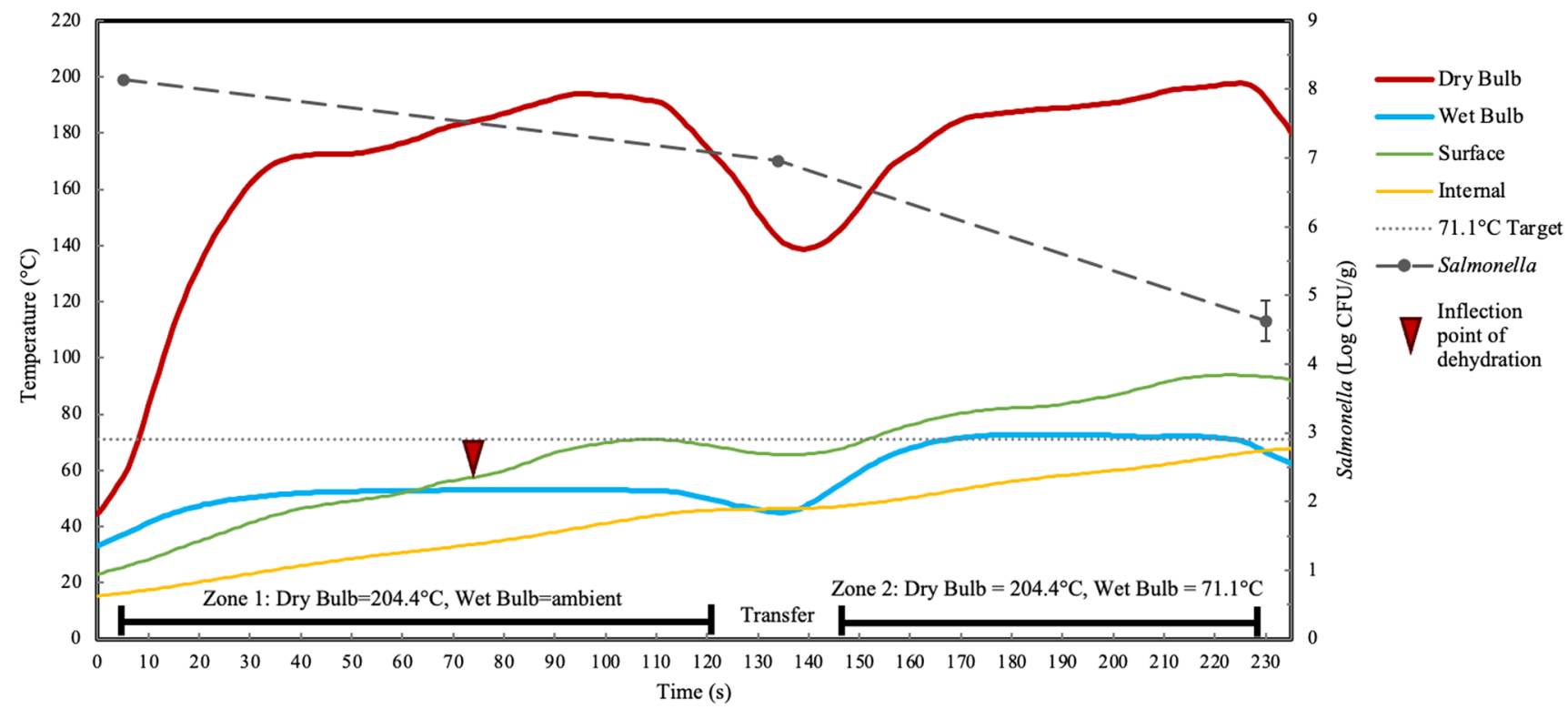

Figure 6. The ability for a single-zone hydrated surface lethality (HSL) process (Process $4,71.1^{\circ} \mathrm{C}$ wet bulb in second zone) to create time-temperature lethal and hydrated product surfaces for reducing surface-inoculated Salmonella on chicken tenders.

\section{Results and Discussion}

\section{The hydrated surface lethality process}

In previous studies, researchers found the product surface and oven wet-bulb temperatures could be graphed and analyzed to identify the transition (i.e., inflection point) from the saturated-surface, constant-rate drying period to the dry-surface, falling-rate drying period (Godsalve et al., 1977; Skjöldebrand,
1980; Hanson, 1990; Sindelar et al., 2016). Based on this work, we surmised that we could graphically analyze process temperature data, confirming when lethal time/temperature conditions existed together with Salmonella reduction data to validate HSL cooking processes for ensuring sufficient reductions of Salmonella on product surfaces during hightemperature, short-duration impingement cooking processes. Based upon previous research findings (Sindelar et al., 2016) and typical industry impingement 


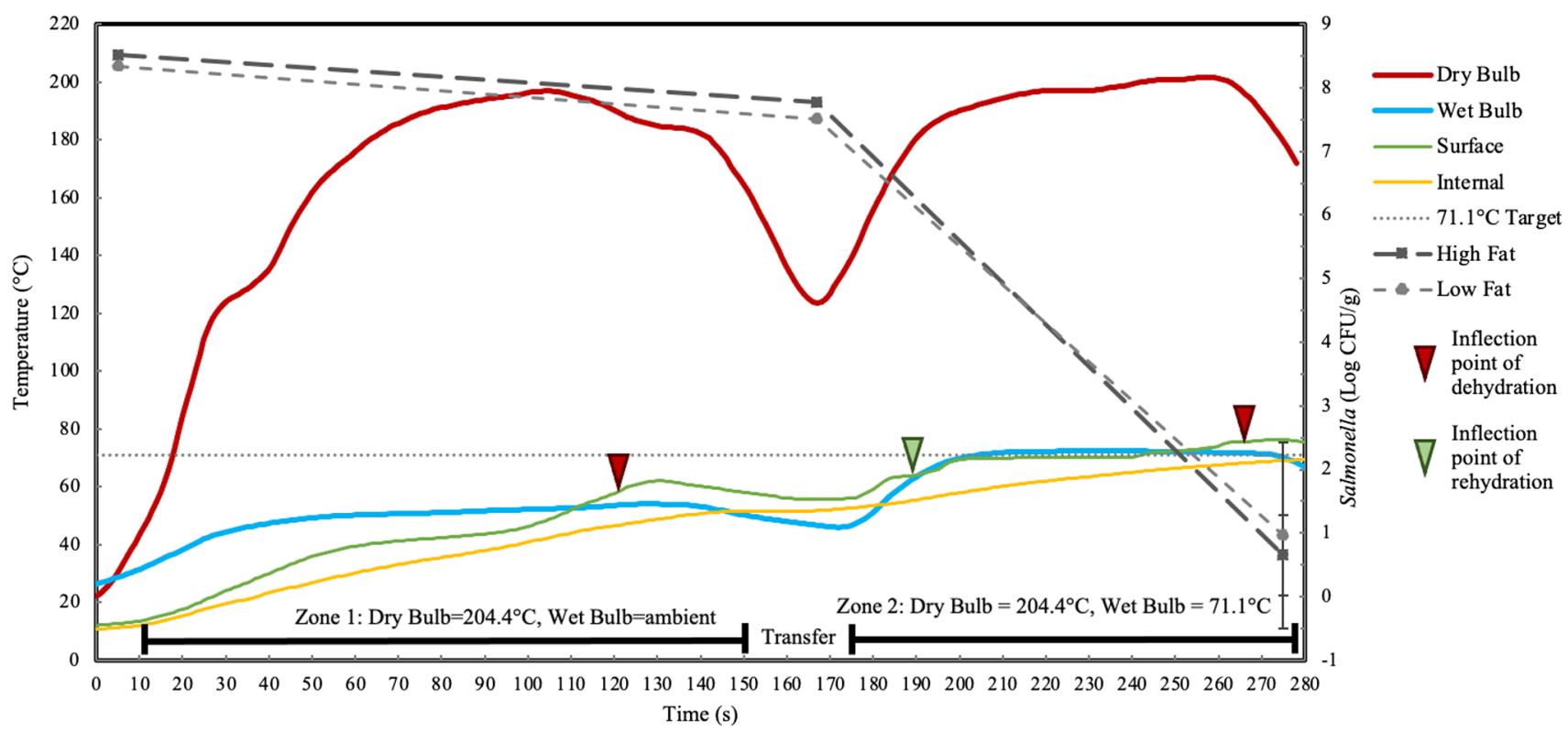

Figure 7. The ability for a single-zone hydrated surface lethality (HSL) process (Process $4,71.1^{\circ} \mathrm{C}$ wet bulb in second zone) to create time-temperature lethal and hydrated product surfaces for reducing surface-inoculated Salmonella on low (10\%) and high (30\%) fat beef patties.

oven operating parameters, the processes in this study tested HSL steps at 2 wet-bulb temperatures $\left(71.1^{\circ} \mathrm{C}\right.$ and $82.2^{\circ} \mathrm{C}$ ) using a pilot-scale impingement oven. Impingement processes were used for this experiment because impingement ovens have the fastest drying rate of any commercially available forced-air convection oven design, thus representing the practical worst case for rapid dehydration of product surfaces with respect to developing desiccated, heat-resistant Salmonella on the product surface.

\section{Description of drying periods}

Cooking meat products in a forced-air convection oven is essentially a high-temperature drying operation (Skjöldebrand, 1980). To better understand the impact these processes have on surface lethality, it is important to appreciate the phases of drying that occur during cooking. Godsalve et al. (1977), Skjöldebrand (1980), and Hanson (1990) found that when meat products were cooked in forced-air convection ovens, the meat surfaces progressed through 3 drying periods: (1) preheat period, (2) constant-rate drying period, and (3) falling-rate drying period.

In the initial preheat period, the product enters the oven with a surface temperature below the dew-point temperature of the air, and therefore water vapor condenses on the surface until the surface reaches or exceeds the dew-point temperature (Hallström et al., 1988). The product remains in this period until the surface heats up to the wet-bulb temperature and then transitions to the constant-rate drying period (Skjöldebrand, 1980). The surface remains hydrated throughout the preheat period.

When the surface temperature reaches the wet-bulb temperature, the constant-rate drying period begins (Hallström et al., 1988; Mujumdar and Devahastin, 2000). This drying period is a saturated-surface drying phase, and the rate of drying during this period is approximately constant (Watson and Harper, 1988). Moisture migrates from the interior to the surface at the same rate or faster than the evaporation rate from the surface. Vaporization occurs at the product surface, and free water with a water activity of 1.0 is always available at the surface to vaporize (Toledo et al., 2018). A continuous layer of water is present over the entire product surface, and the water evaporates from the surface as if the solid matrix is not present (Godsalve et al., 1977; Okos et al., 2007). During this period, the product surface acts like a wet-bulb thermometer, and the cooling effect of evaporation keeps the surface temperature close to the wet-bulb temperature until the end of the constant-rate drying period (Godsalve et al., 1977; Fellows, 2009; Toledo et al., 2018). The constant-rate period continues until water from the interior is no longer freely available at the product surface (Okos et al., 2007). When the surface moisture is reduced to an inflection point known as the critical moisture content, there is an abrupt reduction in the rate of moisture removal, and the product transitions from the constant-rate to the falling-rate drying period (Singh and Heldman, 2009; Toledo et al., 
2018). In common meat industry terms, this transition from the constant- to falling-rate drying periods is known as case-hardening.

The falling-rate drying period occurs when moisture migration from the interior to the surface becomes slower than the evaporation rate from the surface to the air, and thus the surface dries out (Fellows, 2009). The surface is no longer covered with a continuous film of free moisture. The plane of evaporation moves from the surface to inside the product, and water moves from the interior to the surface as a vapor (Okos et al., 2007; Fellows, 2009). The drying rate falls off, and the surface temperature breaks above the wet-bulb temperature (Godsalve et al., 1977; Hanson, 1990; Toledo et al., 2018). At the inflection point where the surface temperature clearly breaks above the wet-bulb temperature, the product surface is no longer fully hydrated, thus increasing the likelihood that a significant population of Salmonella may become desiccated on the surface (Watson and Harper, 1988; Fellows, 2009; Sindelar et al., 2016).

\section{Design hypotheses for hydrated surface lethality processes}

Pathogen lethality values currently available from the literature are valid for predicting reductions for bacteria in the product interior (Juneja et al., 2003; O'Bryan et al., 2006; Sindelar et al., 2016). On the surfaces, however, pathogens may become desiccated and therefore more heat tolerant than the literature values would predict. Gruzdev et al. (2011), for example, found that desiccated Salmonella enterica were able to survive time-temperature conditions that were otherwise lethal for hydrated Salmonella. Importantly, though, these researchers also found that if desiccated Salmonella were rehydrated, the heat tolerance of the desiccated/rehydrated bacteria was returned to the same level as the original, nondesiccated Salmonella. Even so, impingement cooking processes can be designed so that the microclimate around the product is hydrated at lethal temperatures during all or part of the process to ensure sufficient pathogen lethality.

\section{Analysis of thermal profiles and interpretation of graphs}

Representative thermal profiles for the key processes from this study are shown in Figures 1-7. These figures include the oven set points for each zone, process and product temperature profiles, and Salmonella reduction. The inflection points for dehydration and rehydration of the product surfaces, if any, are also noted on the graphs. For dehydration, the inflection point notes the surface transition from a saturated surface to a dry surface, thus signifying the transition from the constant-rate to the falling-rate drying period. If a dry surface was rehydrated during cooking, the inflection point of rehydration notes the point of transition from a dry surface back to a saturated surface. To judge the location of these inflection points, the surface temperatures were compared with the wetbulb temperatures on each thermal profile. When the surface temperature broke above the wet-bulb temperature, this point was designated as an inflection point of dehydration. When an HSL step increased the wet-bulb temperature above the surface temperature so that moisture condenses on the product surfaces, this point was designated as an inflection point of rehydration. In Figures $1-7$, the $\boldsymbol{\nabla}$ symbol identifies the inflection point of dehydration where the surface temperature broke above the wet-bulb temperature. The $\boldsymbol{\nabla}$ symbol notes the inflection point of rehydration, if any, where the wet-bulb temperature was increased above the surface temperature.

The thermal profile in Figure 1 for chicken tenders cooked using Process 1 is a useful example of the graphical analysis that was used for this study. When the surface temperature tracked with the wet-bulb temperature for most of Zone 1, the surface was fully hydrated in the constant-rate drying period during this part of the process. After $85 \mathrm{~s}$, however, the surface temperature increased to the wet-bulb temperature, indicating that the surfaces had dried and transitioned from the constant-rate to the falling-rate drying period $(\nabla$ symbol in Figure 1).

\section{Effectiveness of hydrated surface lethality steps for pathogen reduction}

For the purposes of our study, $\geq 6.5 \log$ reduction (limit of accurate enumeration given inoculation level) was deemed sufficient lethality. With the exception of the chicken tenders for Processes 1 and 4 (Table 3) and the low-fat ground beef and pork patties for Process 1 (Tables 4-5), all other treatments delivered $>6.5 \mathrm{log}$ reduction (Tables 3-5).

Process 1 was a dry-heat, ambient-humidity cooking process with no steam-injected HSL step in either zone. Under ambient-humidity conditions, the wetbulb temperature ranged between $51.7^{\circ} \mathrm{C}$ and $54.4^{\circ} \mathrm{C}$ (Figure 1). This dry-heat process failed to achieve the targeted Salmonella reduction of $\geq 6.5 \log$ for the chicken tenders and for all the low-fat patty products 
(10\% fat). Total average reductions for the low-fat products cooked using Process 1 were $4.0 \mathrm{log}$ for chicken tenders ( $<3 \%$ fat, Table 3), $6.2 \log$ for $10 \%$ fat beef patties (Table 4), $5.8 \log$ for $10 \%$ fat pork patties (Table 5), and $6.3 \log$ for $10 \%$ fat chicken patties (Table 6).

Process 1 was the driest of the 7 processes and thus had the highest likelihood of desiccation for the surface-inoculated Salmonella. As expected, the Salmonella reduction was less than target kill on chicken tenders (4.0 log kill, Table 3), likely due to the dry cooking processes and the resultant desiccation and reduced water activity (Goepfert et al., 1970; Goodfellow and Brown, 1978; Mattick et al., 2000, 2001; Hiramatsu et al., 2005; Buege et al., 2006; Gruzdev et al., 2011). Graphical analysis of the chicken tenders cooked using Process 1 showed that the hot, dry, high-velocity air quickly dried the surfaces of the whole-muscle, low-fat tenders (Figure 1). The rapid surface dehydration presumably created an increased proportion of desiccated, heat-tolerant Salmonella that survived surface temperatures otherwise lethal to hydrated Salmonella. Although the surfaces of the tenders remained hydrated for much of Zone 1, the ambient wet-bulb temperatures of $51.7^{\circ} \mathrm{C}$ to $54.4^{\circ} \mathrm{C}$ were too low to be lethal to Salmonella in the short 2-min dwell time in that zone. After $110 \mathrm{~s}$, near the end of Zone 1, the surface temperature reached $71.1^{\circ} \mathrm{C}$, a temperature that would have been highly lethal to hydrated Salmonella (O'Bryan et al., 2006; USDA, 2017). As shown in Figure 1, however, the Salmonella reduction at the end of Zone 1 was only $1.5 \mathrm{log}$, a low reduction that most likely resulted from increased heat tolerance of desiccated Salmonella.

At the end of Zone 2, the surface temperature of the chicken tenders reached $99.4^{\circ} \mathrm{C}$ (Figure 1), a temperature that would have been instantly lethal to Salmonella if still hydrated. The low overall reduction of only $4.0 \mathrm{log}$, however, indicates that many of the surfaceinoculated Salmonella had become desiccated and thus survived the cooking process (Table 3 ). This result aligns with research by Gruzdev et al. (2011), who found that desiccated Salmonella enterica could survive temperatures of $100^{\circ} \mathrm{C}$ for $60 \mathrm{~min}$.

For Process 1, larger reductions were achieved for the high-fat ground meat (beef, pork, and chicken) patties than for the low-fat ones (Tables 4-6). Although the specific mechanism is still not clear, the higher fat levels most likely kept the surfaces moist enough to prevent significant desiccation. In contrast, the low-fat, whole-muscle chicken tenders and the low-fat patties were more prone to rapid surface dehydration, presumably resulting in an increased proportion of desiccated, heat-tolerant Salmonella for the lower-fat products.

Processes 2 and 7 had HSL steps in both zones, using steam injection to control the wet-bulb temperature in both zones at $71.1^{\circ} \mathrm{C}$ for Process 2 (Figure 2) or $82.2^{\circ} \mathrm{C}$ for Process 7 (Figure 3). These 2 double-zone HSL processes had the highest and most consistent log reductions of all 7 processes (Tables 3-6, Figure 8). Salmonella reductions for Processes 2 and 7 were $\geq 6.5 \log$ for all products. Although the reductions for these 2 processes exceeded the $6.5 \mathrm{log}$ target and were not significantly different $(P>0.05)$, Process 7 generally provided slightly greater lethality than Process 2, most likely because Process 7 used a higher wet-bulb temperature for its HSL steps. Processes 2 and 7 used the shortest cooking time of $3.0 \mathrm{~min}$, compared with $3.5 \mathrm{~min}$ for Processes 3 to 6 and $4.0 \mathrm{~min}$ for Process 1 , but still exceeded the targeted $\geq 6.5 \mathrm{log}$ reduction of Salmonella for all products investigated. Graphical analysis of Processes 2 and 7 showed that the product surface temperatures were $\geq 71.1^{\circ} \mathrm{C}$ before the inflection point of dehydration was reached, and thus the surfaces achieved a highly lethal surface temperature of $71.1^{\circ} \mathrm{C}$ under fully hydrated conditions for all products cooked using Processes 2 and 7 (Figures 2-3) (USDA, 2017). Both of these two-zone HSL processes, then, were highly effective in achieving sufficient Salmonella lethality before desiccation, resulting in the highest, most consistent log reductions of all the tested processes (Figure 8).

Processes 5 and 6 were both single-step HSL processes using an $82.2^{\circ} \mathrm{C}$ wet-bulb temperature for the HSL step. Process 5 used the HSL step in Zone 2, after a dry-heat first zone, whereas Process 6 used the HSL step in Zone 1, prior to a dry-heat second zone. Process 5 was intended to determine whether pathogens desiccated in Zone 1 could be rehydrated and inactivated using an HSL step in Zone 2. In contrast, Process 6 was intended to determine whether an HSL step in Zone 1 would provide enough reduction in the first zone to overcome the presumably lower reductions of a subsequent dry-heat step in Zone 2.

As shown in Tables 3-6, Processes 5 and 6 both achieved $\geq 6.5 \log$ Salmonella reductions for all 7 products. Although both processes were similarly effective, it is instructive to graphically analyze the temperature profiles for chicken tenders in Figures 4 and 5 to observe how the 2 processes achieved similar reductions in different ways. For chicken tenders cooked in Process 6, the product entering Zone 1 was exposed to an HSL wet-bulb temperature that rapidly increased 


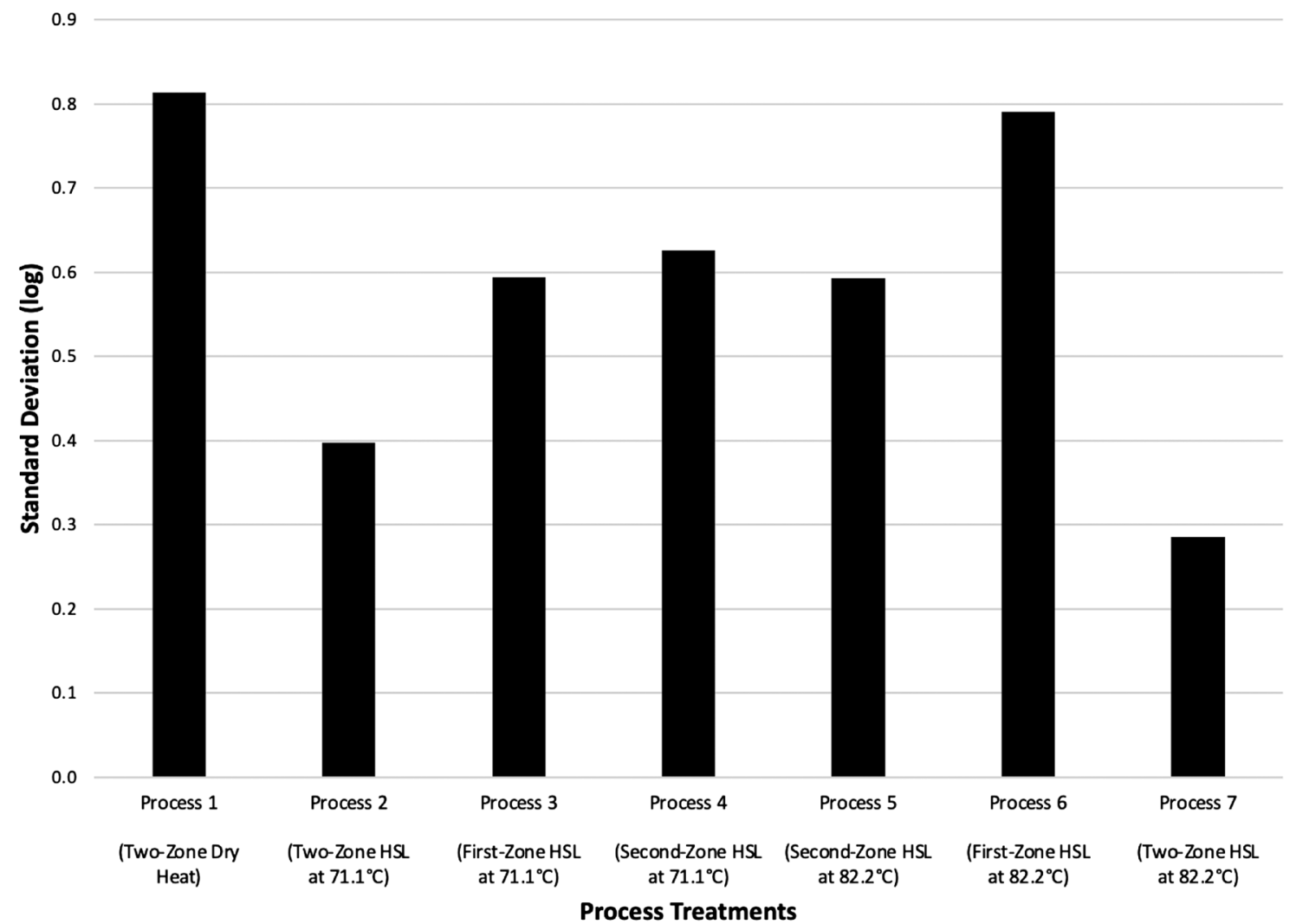

Figure 8. Average least-squares means with standard deviations for each process combining all product endpoint means, including chicken tenders, beef patties, pork patties, and chicken patties.

to its set point of $82.2^{\circ} \mathrm{C}$ (Figure 5). The product surface remained hydrated in the constant-rate drying period throughout Zone 1 and reached a highly lethal temperature of $72.2^{\circ} \mathrm{C}$ at the end of the zone, resulting in a midpoint Salmonella reduction of $4.8 \mathrm{log}$ in $1.75 \mathrm{~min}$ (Figure 5). Zone 2 was a dry-heat zone, and the ambient wet-bulb temperature drifted at a sublethal temperature of $51.7^{\circ} \mathrm{C}$ to $54.4^{\circ} \mathrm{C}$ in this zone. These dry-heat conditions desiccated the surface of the chicken tenders almost immediately upon entering Zone 2. At $145 \mathrm{~s}$, the surface temperature broke above the wet-bulb temperature, indicating that at this point, the surface had begun to dehydrate and had transitioned from the constant-rate to the falling-rate drying period. The surface temperature continued to rise to approximately $90.6^{\circ} \mathrm{C}$ at the discharge of Zone 2, a temperature that would have been highly lethal to hydrated Salmonella. However, the dry conditions likely desiccated remaining viable Salmonella such that the additional $\log$ reduction in Zone 2 was only $2.2 \mathrm{log}$. Regardless, the Zone $1 \mathrm{HSL}$ step using an $82.2^{\circ} \mathrm{C}$ wet-bulb temperature in combination with a less lethal second zone using dry heat was still sufficient to achieve an overall reduction of $7.0 \log$ (Table 3 ).
For Process 5, Zone 1 was dry heat followed by an HSL step in Zone 2 using an $82.2^{\circ} \mathrm{C}$ wet-bulb temperature. In the first zone, the chicken tenders were exposed to dry-heat conditions in which the ambient wet-bulb temperature fluctuated at a sublethal temperature of $51.7^{\circ} \mathrm{C}$ to $54.4^{\circ} \mathrm{C}$ (Figure 4). Although Zone 1 was a dry-heat zone, the surface temperature still tracked below the wet-bulb temperature until $115 \mathrm{~s}$, indicating that the surface remained hydrated in the constant-rate drying period for most of Zone 1 but at a sublethal surface temperature of only $51.7^{\circ} \mathrm{C}$. At the discharge of Zone 1, the surface temperature did achieve $57.2^{\circ} \mathrm{C}$, which would have been a lethal temperature for Salmonella if held at that temperature for a much longer time (USDA, 1999). However, given the short duration, low surface temperature, and dehydrated surface conditions, the first zone was ineffective, resulting in only a $1.1 \mathrm{log}$ reduction. As noted in Figure 4, the surface temperature of the chicken tenders exceeded the wet-bulb temperature near the end of Zone 1 at $115 \mathrm{~s}$, indicating that the surface had dried and transitioned from the constant-rate to the fallingrate drying period just before the end of the first zone. At the beginning of Zone 2, the product surfaces were 
immediately subjected to an HSL step wherein the wetbulb temperature quickly rose to the $82.2^{\circ} \mathrm{C}$ set point. The wet-bulb temperature increased sharply above the surface temperature, thus condensing moisture on the product surfaces and presumably rehydrating any desiccated Salmonella. This inflection point of rehydration occurred at approximately $165 \mathrm{~s}$, abruptly shifting the surfaces from the falling-rate drying period back into the constant-rate drying period at a highly lethal temperature of $>71.1^{\circ} \mathrm{C}$ for most of Zone 2 (Figure 4). Upon rehydration, the heat tolerance of any desiccated/rehydrated Salmonella reverted to a level similar to hydrated Salmonella (Gruzdev et al., 2011). The high $82.2^{\circ} \mathrm{C}$ wet-bulb HSL step in Zone 2 , then, functioned as intended, rehydrating and inactivating desiccated Salmonella, resulting in an overall $\log$ reduction of $7.0 \mathrm{log}$ for Process 5. These findings align with previous studies wherein researchers found that heat tolerances were similar for hydrated and desiccated/rehydrated Salmonella (Goodfellow and Brown, 1978; Gruzdev et al., 2011).

Processes 3 and 4 were both single-step HSL processes using a $71.1^{\circ} \mathrm{C}$ wet-bulb temperature for the HSL step. Process 3 used the HSL step in Zone 1, prior to a dry-heat zone. This process was intended to determine whether a $71.1^{\circ} \mathrm{C}$ wet-bulb HSL step in Zone 1 would provide enough reduction to offset the presumably lower reductions of a subsequent dry-heat step in Zone 2. Process 4 used a $71.1^{\circ} \mathrm{C}$ wet-bulb HSL step in Zone 2, after a dry-heat first zone. This process was intended to determine whether Salmonella desiccated in an initial dry-heat zone could be rehydrated and inactivated using a $71.1^{\circ} \mathrm{C}$ wet-bulb HSL step in Zone 2. Processes 3 and 4 achieved Salmonella reductions $\geq 6.5 \log$ for all products except, importantly, for chicken tenders cooked using Process 4 (Tables 3-6). Process 4 achieved a reduction of only $3.5 \mathrm{log}$ for chicken tenders. This reduction was the lowest of all products and processes in this study, although it was not significantly different from the $4.0 \mathrm{log}$ reduction for chicken tenders cooked in Process 1, which used dry heat in both zones $(P<0.05)$. In addition, the total cooking time for Process 4 was 3.5 min compared with $4.0 \mathrm{~min}$ for Process 1, suggesting that the shorter cooking time for Process 4 contributed to the lower reduction for this process.

Graphical analysis of the chicken tenders cooked using Process 4 explains the ineffectiveness of the $71.1^{\circ} \mathrm{C}$ wet-bulb HSL step used in Zone 2 of this process (Figure 6). Process 4 used a dry-heat, ambienthumidity step in Zone 1 followed by a $71.1^{\circ} \mathrm{C}$ wet-bulb step in Zone 2 that was intended to be an HSL step.
Upon entering Zone 1, the product surfaces were exposed to dry-heat conditions in which the wet-bulb temperature drifted in a sublethal range of $51.7^{\circ} \mathrm{C}$ to $54.4^{\circ} \mathrm{C}$ (Figure 6). At approximately $75 \mathrm{~s}$, the product surface temperature broke above the wet-bulb temperature, indicating that the surface had begun to dry and had transitioned from the constant-rate to the fallingrate drying period approximately halfway through Zone 1 . The surfaces, then, were hydrated for the first half of Zone 1 but at a sublethal temperature. At the end of Zone $1(\sim 120 \mathrm{~s})$, the surface temperature had reached $71.1^{\circ} \mathrm{C}$, which would have been highly lethal to Salmonella if still hydrated (USDA, 1999). At this point, however, the surfaces were already dried, resulting in only a $1.3 \log$ reduction in the first zone. Upon entering Zone $2(\sim 145 \mathrm{~s})$, the product was exposed to a $71.1^{\circ} \mathrm{C}$ wet-bulb temperature, which was intended to serve as an HSL step to rehydrate any desiccated Salmonella at a lethal temperature. However, as shown in Figure 6, when the chicken tenders entered Zone 2, the surface temperature was already well above the $71.1^{\circ} \mathrm{C}$ wet-bulb temperature used for the HSL step, and therefore moisture did not condense on the product surfaces. For an HSL step to be effective, the wet-bulb temperature must be higher than the surface temperature so that moisture condenses on the product surfaces to rehydrate any desiccated Salmonella at a lethal temperature. In Process 4, the wet-bulb temperature in Zone 2 did not exceed the surface temperature of the chicken tenders, and therefore moisture did not condense on the dry surfaces. As a result, the $71.1^{\circ} \mathrm{C}$ wet-bulb HSL step in Zone 2 was ineffective, resulting in a cumulative Salmonella reduction of only $3.5 \mathrm{log}$ for Process 4. This result aligns with the findings of Sindelar et al. (2016), who found similar results for chicken tenders cooked using this same process in a previous study on impingement cooking.

As shown in Figure 6, the surface temperature for the chicken tenders cooked using Process 4 was $71.1^{\circ} \mathrm{C}$ at the discharge of Zone 1 and $93.3^{\circ} \mathrm{C}$ at the discharge of Zone 2, surface temperatures that would have been otherwise highly lethal for hydrated Salmonella. However, the dry conditions in Zone 1 apparently created a large proportion of desiccated, heat-tolerant Salmonella that survived these high surface temperatures, resulting in a $\log$ reduction of only $3.5 \mathrm{log}$. In contrast to the chicken tender results, Process 4 resulted in sufficient Salmonella reductions for all of the patty products (Tables 4-6). Figure 7 shows the surface rehydration for beef patties using a $71.1^{\circ} \mathrm{C}$ HSL step in Zone 2 of Process 4 . The patty surfaces were hydrated in the constant-rate drying period for most of Zone 1 
but at a sublethal temperature of $51.7^{\circ} \mathrm{C}$. The patty surfaces dried near the end of Zone 1 at approximately 120 s, presumably desiccating the Salmonella. However, in contrast to the chicken tenders, the sharp increase in the wet-bulb temperature to the $71.1^{\circ} \mathrm{C}$ HSL set point quickly increased the wet-bulb temperature above the surface temperature of the beef patties, thus rehydrating the surfaces at a lethal temperature early in Zone 2 (190 s). At this point, desiccated Salmonella would have been rehydrated at a highly lethal temperature of $71.1^{\circ} \mathrm{C}$. The surface temperature of the beef patties remained at $71.1^{\circ} \mathrm{C}$ under hydrated conditions for most of Zone 2, resulting in a $7.4 \mathrm{log}$ reduction of Salmonella in 10\% fat beef patties and $7.9 \log$ reduction for $30 \%$ fat beef patties (Table 4). The more than $7 \log$ Salmonella reduction for the beef patty products using Process 4 was significantly greater than the $3.5 \log$ reduction for chicken tenders using the same cooking process, demonstrating the importance of validating the HSL steps used in impingement processes.

\section{Influence of hydrated surface lethality steps on variability of Salmonella reductions}

The mean-average standard deviations for Salmonella reductions across all products for each process are shown in Figure 8. Processes 2 and 7, which had wet-bulb controlled HSL steps in both zones, had the lowest average standard deviations, thus providing the most consistent Salmonella reductions across all products. The highest standard deviation was for Process 1 using dry-heat only with no HSL steps. These results demonstrate that impingement processes that use wet-bulb controlled HSL steps in all zones provide greater and more consistent Salmonella reductions than processes using only dry heat.

\section{Influence of fat levels on process lethality}

When products were cooked using only dry heat in Process 1 , the low-fat (10\% fat) beef, pork, and chicken patties had lower total Salmonella reductions $(\leq 5.8$ $\log$ ) than the patties with higher fat levels of $20 \%$ or $30 \%$ (Tables 4-6). The dry-heat process combined with the lower fat levels promoted rapid surface dehydration, presumably resulting in a higher proportion of desiccated, heat-tolerant Salmonella on the surfaces of low-fat patties than on high-fat patties. For example, the total Salmonella reduction for $10 \%$ fat pork patties cooked using the dry-heat Process 1 was $5.8 \mathrm{log}$ compared with $7.1 \log$ for $30 \%$ fat pork patties cooked using the same process (Table 5). The low-fat patties were more prone to surface dehydration and Salmonella desiccation than the high-fat patties, leading to lower reductions for the low-fat patties.

When HSL steps were used in both zones (Processes 2 and 7), sufficient reductions of $\geq 6.5 \mathrm{log}$ were achieved for all of the low- and high-fat patties, and the $\log$ reductions were similar for both fat levels (Tables 4-6). For example, when pork patties were cooked in Process 2 using a $71.1^{\circ} \mathrm{C}$ wet-bulb HSL step in both zones, the Salmonella reductions for the lowand high-fat levels were almost identical, with reductions of $8.0 \log$ for $10 \%$ fat and $7.9 \log$ for $30 \%$ fat pork patties (Table 5). This finding contrasts with studies that suggest that fat is protective to pathogens during thermal treatments (USDA, 1999, 2017; Doyle and Mazzotta, 2000). However, in the thermal death time studies to create D- and z-values, desiccation was not considered.

\section{Implications for production processes for impingement ovens}

In this study, the dry-heat Process 1 rapid cook with no steam injection failed to achieve sufficient reductions of $\geq 6.5 \mathrm{log}$ on product surface for the whole-muscle chicken tenders and for the low-fat beef, pork, and chicken patties. Using dry-heat, ambient-humidity impingement cooking processes in industrial settings, then, increases the risk of desiccated Salmonella surviving on product surfaces, even if high dry-bulb temperatures are used and products are cooked to high internal product temperatures. Therefore, dry-heat, ambienthumidity cooking processes are not recommended for short-duration (e.g., 4 min) impingement ovens.

Single-zone HSL steps using wet-bulb temperatures of $71.1^{\circ} \mathrm{C}$ and $82.2^{\circ} \mathrm{C}$ were effective when the wet-bulb temperatures were high enough to maintain hydrated surface conditions at lethal temperatures for a sufficient time. If product surfaces were dehydrated early in the process, then subsequent single-zone HSL steps were only effective if the wet-bulb temperature was high enough to exceed the surface temperature so that moisture condensed on the product surfaces at a highly lethal temperature, thus rehydrating and inactivating any desiccated Salmonella. If a single-step HSL process is used in an industry impingement process, then it is recommended that the effectiveness of the HSL step be validated using graphical analysis of the surface and wet-bulb temperatures to ensure that the wet-bulb temperature used in the HSL step is high enough to rehydrate the product surfaces at a lethal time-temperature. 


\section{Recommendations for validating hydrated surface lethality processes}

The most reliable impingement cooking processes in this study were those that used HSL steps in both zones (i.e., for the entire process). When HSL steps with controlled wet-bulb temperatures of either $71.1^{\circ} \mathrm{C}$ or $82.2^{\circ} \mathrm{C}$ were used in both zones, sufficient Salmonella reductions of $\geq 6.5 \log$ were reliably achieved for all products. Based on these results, we recommend that impingement processes use HSL steps with wet-bulb temperatures $\left(T_{w b}\right)$ of $\geq 71.1^{\circ} \mathrm{C}$ in all zones to reliably achieve Salmonella reductions of $\geq 6.5 \mathrm{log}$ on product surfaces for impingement processes with cooking time $(t) \geq 3.0 \mathrm{~min}$. HSL steps that use wet-bulb temperatures higher than $71.1^{\circ} \mathrm{C}$ or total cooking times longer than 3 min will provide an additional margin of safety.

The validation criteria for surface lethality, then, would be listed as follows:

1. $T_{w b} \geq 71.1^{\circ} \mathrm{C}$ for entire process

2. $t \geq 3 \mathrm{~min}$

Using these criteria, an impingement process is considered validated for surface lethality if the wet-bulb temperature is controlled at $\geq 71.1^{\circ} \mathrm{C}$ in all zones and the cooking time is $\geq 3 \mathrm{~min}$. The surface temperature would not have to be measured to validate processes that use these criteria. However, if a combination of both dryheat and HSL steps were used in a process, or the overall process time for an HSL process was shorter than $3 \mathrm{~min}$, the surface and wet-bulb temperatures during the process would have to be measured and graphically analyzed to validate the process for confirming sufficient surface lethality.

As an example, Process 4 was used to cook beef patties using dry heat in Zone 1 and an HSL step using a $71.1^{\circ} \mathrm{C}$ wet-bulb temperature in Zone 2 (Figure 7). The data in Figure 7 can be graphically analyzed to validate the Zone $2 \mathrm{HSL}$ step as follows: HSL time $T_{s} \leq$ $T_{w b} \geq 41 \mathrm{~s}$ at $T_{s}=71.1^{\circ} \mathrm{C}$.

For this example, the required HSL time-defined as the time that the surface temperature $\left(T_{s}\right)$ is less than the wet-bulb temperature $\left(T_{w b}\right)$-must be $41 \mathrm{~s}$ or longer at a surface temperature of $71.1^{\circ} \mathrm{C}$.

This HSL time requirement of $41 \mathrm{~s}$ is based on published lethality data for Salmonella in ground beef from a study by Juneja et al. (2003). These researchers used a nonlinear survival model to predict that a holding time of $\geq 41 \mathrm{~s}$ at $71.1^{\circ} \mathrm{C}$ was required for a $6.5 \mathrm{log}$ reduction of Salmonella in ground beef $(25 \%$ fat, no $\mathrm{NaCl})$. Graphical analysis of the surface and wet-bulb temperatures in Figure 7 shows that, in Zone 2 from 200 to
$255 \mathrm{~s}$, the surface temperature was at $71.1^{\circ} \mathrm{C}$ without breaking above the wet-bulb temperature during that time. As such, the surface was fully hydrated for $55 \mathrm{~s}$ at $71.1^{\circ} \mathrm{C}$, thus exceeding the $41 \mathrm{~s}$ required for validation of surface lethality. As shown in Table 4, the actual Salmonella reductions for beef patties cooked using Process 4 were $7.4 \log$ for $10 \%$ fat and $7.9 \log$ for $30 \%$ fat patties, thus supporting the prediction that this HSL step would provide sufficient surface lethality for beef patties.

To validate high-temperature, short-duration impingement processes for surface lethality, we recommend that the required HSL times for process validations be based on challenge studies or nonlinear survival models, not published D-values that assume a linear survival curve. In this study, we found that the times required for Salmonella reductions of $\geq 6.5 \log$ were often longer than predictions derived from linear models based on published D-values. For example, McMinn et al. (2018) measured a D-value for ground beef of $4.2 \mathrm{~s}$ for Salmonella at $71.1^{\circ} \mathrm{C}$, thus predicting a 27.3-s time for a $6.5 \log$ reduction, which is shorter than the actual times required in this study. As another example, the time-temperature tables in USDA Appendix A (USDA, 2017) used D-values from linear survival curves to predict a Salmonella reduction of $6.5 \log$ in $0 \mathrm{~s}$ at $71.1^{\circ} \mathrm{C}$ for beef and a reduction of $7.0 \log$ in $16.2 \mathrm{~s}$ at $71.1^{\circ} \mathrm{C}$ for chicken $(10 \%$ fat $)$-both of which are well short of the actual times needed for 6.5 and $7.0 \mathrm{log}$ Salmonella reductions that we found in this study (Tables 4 and 6). From these observations, we concluded that predicted reductions based on D-values from linear survival curves are not appropriate for short-duration, high-temperature impingement processes. These observations align with Juneja et al. (2003), who concluded that predictions based solely on D-values calculated from linear portions of survival curves are often biased because the shoulders at the beginning of the survival curves and the tailing at the end are left out of the calculations. Impingement processes are so short that every second counts, and therefore the effects of these biases become more pronounced due to the short cooking times. As such, we concur with Juneja et al. (2003), who recommended that calculations of predicted times for specific reductions be based on nonlinear survival models, not linear-based D-values.

\section{Conclusions}

For most precooked meat and poultry products, cooking processes are the primary critical control point 
for the destruction of vegetative pathogens. As such, cooking processes must act as a firewall between pathogen-laden raw products and pathogen-free cooked products. Meat processors depend on effective cooking processes to reliably destroy the vegetative pathogens that invariably exist on the surface and interior of raw products. HSL steps using wet-bulb temperatures of $71.1^{\circ} \mathrm{C}$ or higher in all zones of impingement cooking processes proved effective for ensuring that surface-inoculated Salmonella were subjected to lethal time-temperature combinations under hydrated conditions. Because impingement ovens represent the practical worstcase for rapid dehydration of product surfaces in forced-air convection continuous ovens, the HSL steps validated in this study can safely be used as validated HSL steps for impingement, spiral, and cross-flow forced-air convection ovens.

This research demonstrated that impingement ovens using dry-heat cooking processes were capable of rapidly desiccating Salmonella on the surfaces of meat products and that significant numbers of these desiccated, heat-tolerant Salmonella were able to survive dry-heat cooking processes. Therefore, the use of product internal temperatures alone as predictors of overall process lethality is inadequate for ensuring sufficient pathogen reduction-industry processors must consider surface lethality when evaluating the safety of impingement cooking processes. To ensure the most reliable surface lethality, we recommend that impingement cooking processes incorporate validated HSL steps with wet-bulb temperatures of $\geq 71.1^{\circ} \mathrm{C}$ for the entire cooking process.

\section{Acknowledgments}

The authors acknowledge Dennis Seman for his support on the statistical analysis of the data. The authors also thank Brandon Wanless, Max Golden, Quinn Huibregtse, Jie Yin Lim, and Sarah Engstrom for their technical assistance. Funding for this project was gratefully received from ConAgra Foods, Hormel Foods, Johnsonville Sausage, Jones Dairy Farm, Sugar Creek Packing, and Tyson Foods.

\section{Literature Cited}

Aljarallah, K. M., and M. R. Adams. 2007. Mechanisms of heat inactivation in Salmonella serotype Typhimurium as affected by low water activity at different temperatures. J. Appl. Microbiol. 102:153-160. https://doi.org/10.1111/j.1365-2672. 2006.03054.x.
AOAC. 2008. Moisture and fat in meats. Official method 2008.06. In: Official methods of analysis. 20th edition. AOAC, Arlington, VA. p. 931.

Buege, D. R., G. Searls, and S. C. Ingham. 2006. Lethality of commercial whole-muscle beef jerky manufacturing processes against Salmonella serovars and Escherichia coli $\mathrm{O} 157: \mathrm{H7}$. J. Food Protect. 69:2091-2099. https://doi.org/10.4315/ 0362-028x-69.9.2091.

Burnett, S. L., E. R. Gehm, W. R. Weissinger, and L. R. Beuchat. 2000. Survival of Salmonella in peanut butter and peanut butter spread. J. Appl. Microbiol. 89:472-477. https://doi.org/10. 1046/j.1365-2672.2000.01138.x.

Doyle, M. E., and A. S. Mazzotta. 2000. Review of studies on the thermal resistance of salmonellae. J. Food Protect. 63:779 795. https://doi.org/10.4315/0362-028x-63.6.779.

Fellows, P. J. 2009. Dehyration. In: Food processing technology: Principles and practice. 3rd ed. Woodhead Publishing, Cambridge, UK. p. 481-521.

Godsalve, E. W., E. A. Davis, J. Gordon, and H. T. Davis. 1977. Water loss rates and temperature profiles of dry cooked bovine muscle. J. Food Sci. 42:1038-1045. https://doi.org/10.1111/j. 1365-2621.1977.tb12662.x.

Goepfert, J. M., I. K. Iskander, and C. H. Amundson. 1970. Relation of the heat resistance of Salmonellae to the water activity of the environment. Appl. Microbiol. 19:429-433.

Goodfellow, S. J., and W. L. Brown. 1978. Fate of Salmonella inoculated into beef for cooking. J. Food Protect. 41:598-605. https://doi.org/10.4315/0362-028X-41.8.598.

Gruzdev, N., R. Pinto, and S. Sela. 2011. Effect of desiccation on tolerance of Salmonella enterica to multiple stresses. Appl. Environ. Microb. 77:1667-1673. https://doi.org/10.1128/ AEM.02156-10.

Hallström, B., C. Skjöldebrand, and C. Trägårdh. 1988. Heat transfer and solid foods. In: Heat transfer and food products. Elsevier Applied Science, New York. p. 84-129.

Hanson, R. E. 1990. Cooking technology. In: Proceedings of the 43rd Reciprocal Meat Conference. American Meat Science Association, Mississippi State, MS. p. 109-116.

Hiramatsu, R., M. Matsumoto, K. Sakae, and Y. Miyazaki. 2005. Ability of Shiga toxin-producing Escherichia coli and Salmonella spp. to survive in a desiccation model system and in dry foods. Appl. Environ. Microb. 71:6657-6663. https://doi.org/10.1128/AEM.71.11.6657-6663.2005.

Jay, J. M., M. J. Loessner, and D. A. Golden. 2005. Modern food microbiology. 7th ed. Springer, New York.

Juneja, V. K., H. M. Marks, and T. Mohr. 2003. Predictive thermal inactivation model for effects of temperature, sodium lactate, $\mathrm{NaCl}$, and sodium pyrophosphate on Salmonella serotypes in ground beef. Appl. Environ. Microb. 69:5138-5156. https:// doi.org/10.1128/aem.69.9.5138-5156.2003.

Kang, D.-H., and D. Y. C. Fung. 2000. Application of thin agar layer method for recovery of injured Salmonella typhimurium. Int. J. Food Microbiol. 54:127-132. https://doi.org/10.1016/ S0168-1605(99)00174-9.

Leffler, T. P., C. R. Moser, B. J. McManus, J. J. Urh, J. T. Keeton, and A. Claflin. 2008. Determination of moisture and fat in meats by microwave and nuclear magnetic resonance analysis: Collaborative study. J. AOAC Int. 91:802-810. 
Mattick, K. L., F. Jorgensen, J. D. Legan, H. M. Lappin-Scott, and T. J. Humphrey. 2000. Habituation of Salmonella spp. at reduced water activity and its effect on heat tolerance. Appl. Environ. Microb. 66:4921-4925. https://doi.org/10. 1128/aem.66.11.4921-4925.2000.

Mattick, K. L., F. Jørgensen, P. Wang, J. Pound, M. H. Vandeven, L. R. Ward, J. D. Legan, H. M. Lappin-Scott, and T. J. Humphrey. 2001. Effect of challenge temperature and solute type on heat tolerance of Salmonella serovars at low water activity. Appl. Environ. Microb. 67:4128-4136. https://doi. org/10.1128/AEM.67.9.4128-4136.2001.

McMinn, R. P., A. M. King, A. L. Milkowski, R. Hanson, K. A. Glass, and J. J. Sindelar. 2018. Processed meat thermal processing food safety-Generating $D$-values for Salmonella, Listeria monocytogenes, and Escherichia coli. Meat Muscle Biol. 2:168-179. https://doi.org/10.22175/ mmb2017.11.0057.

Mujumdar, A. S., and S. Devahastin. 2000. Fundamental principles of drying. In: Mujumdar's practical guide to industrial drying. Exergex Corporation, Montreal, Canada. p. 1-22.

O'Bryan, C. A., P. G. Crandall, E. M. Martin, C. L. Griffis, and M. G. Johnson. 2006. DHeat resistance of Salmonella spp., Listeria monocytogenes, Escherichia coli 0157:H7 and Listeria innocua M1, a potential surrogate for Listeria monocytogenes, in meat and poultry: A review. J. Food Sci. 71:R23-R30. https://doi.org/10.1111/j.1365-2621.2006.tb15639.x.

Okos, M. R., O. Campanella, G. Narsimhan, R. K. Singh, and A. C. Weitnauer. 2007. Food dehydration. In: Handbook of food engineering. CRC Press Taylor \& Francis, Boca Raton, FL. p. 601-744.

Sindelar, J. J., K. Glass, and R. Hanson. 2016. Investigating the development of thermal processing tools to improve the safety of ready-to-eat meat and poultry products. North American Meat Institute Foundation, Washington, DC.

Sindelar, J. J., R. Hanson, K. A. Glass, A. M. Milkowski, R. P. McMinn, and J. Nehls. 2020. Hydrated surface lethality. Univeristy of Wisconsin-Madison Division of Extension report. https://livestock.extension.wisc.edu/article-search//. (Accessed 16 December 2020.)

Singh, R. P., and D. R. Heldman. 2009. Dehydration. In: Introduction to food engineering. 4th ed. Elsevier/Academic Press, Burlington, MA. p. 653-687.

Skjöldebrand, C. 1980. Convection oven frying: Heat and mass transfer between air and product. J. Food Sci. 45:1354 1358. https://doi.org/10.1111/j.1365-2621.1980.tb06553.x.

Toledo, R. T., R. K. Singh, and F. Kong. 2018. Dehydration. In: Fundamentals of food process engineering. 4th ed. Springer International Publishing, Cham, Switzerland. p. 321-354.

USDA. 1999. Appendix A: Compliance guidelines for meeting lethality performance standards for certain meat and poultry products. United States Department of Agriculture, Washington, DC.

USDA. 2017. FSIS Salmonella compliance guidelines for small and very small meat and poultry establishments that produce ready-to-eat (RTE) products and revised Appendix A. United States Department of Agriculture, Washington, DC.

van Asselt, E. D., and M. H. Zwietering. 2006. A systematic approach to determine global thermal inactivation parameters for various food pathogens. Int. J. Food Microbiol. 107:7382. https://doi.org/10.1016/j.ijfoodmicro.2005.08.014.

Watson, E. L., and J. C. Harper. 1988. Dehydration. In: Elements of food engineering. 2nd ed. Van Nostrand Reinhold, New York. p. 252-285. 